\title{
Vibrational spectroscopic force field studies of dimethyl sulfoxide and hexakis(dimethyl sulfoxide)scandium(III) iodide, and crystal and solution structure of the hexakis(dimethyl sulfoxide)scandium(III) ion $\dagger$
}

\author{
Mikhail Yu. Skripkin, ${ }^{a, b}$ Patric Lindqvist-Reis, ${ }^{c}$ Alireza Abbasi, ${ }^{a}$ János Mink,,${ }^{d, f}$ \\ Ingmar Persson ${ }^{e}$ and Magnus Sandström*a \\ ${ }^{a}$ Department of Structural Chemistry, Stockholm University, SE-106 91, Stockholm, Sweden. \\ E-mail:magnuss@struc.su.se \\ ${ }^{b}$ Department of Chemistry, St. Petersburg State University, Universitetsky pr., 26, 198904, St. \\ Petersburg, Russia \\ ${ }^{c}$ Institut für Nukleare, Forschungszentrum Karlsruhe, P.O. Box 3640, D-76021, Karlsruhe, \\ Germany \\ ${ }^{d}$ Department of Molecular Spectroscopy, Chemical Research Center of the Hungarian Academy \\ of Science, P.O. Box 77, H-1525, Budapest, Hungary \\ e Department of Chemistry, Swedish University of Agricultural Sciences, P.O. Box 7015, SE-750 \\ 07, Uppsala, Sweden

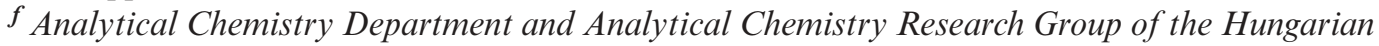 \\ Academy of Sciences, University of Veszprém, P.O. Box 158, Hungary
}

Received 1st September 2004, Accepted 20th October 2004

First published as an Advance Article on the web 8th November 2004

\begin{abstract}
Hexakis(dimethyl sulfoxide)scandium(III) iodide, $\left[\mathrm{Sc}\left(\mathrm{OS}\left(\mathrm{CH}_{3}\right)_{2}\right)_{6}\right] \mathrm{I}_{3}$ contains centrosymmetric hexasolvated scandium(III) ions with an Sc-O bond distance of 2.069(3) Å. EXAFS spectra yield a mean Sc-O bond distance of 2.09(1) Å for solvated scandium(III) ions in dimethyl sulfoxide solution, consistent with six-coordination. Raman and infrared absorption spectra have been recorded, also of the deuterated compound, and analysed by means of normal coordinate methods, together with spectra of dimethyl sulfoxide. The effects on the vibrational spectra of the weak intermolecular $\mathrm{C}-\mathrm{H} \cdots \mathrm{O}$ interactions and of the dipole-dipole interactions in liquid dimethyl sulfoxide have been evaluated, in particular for the S-O stretching mode. The strong Raman band at $1043.6 \mathrm{~cm}^{-1}$ and the intense IR absorption at $1062.6 \mathrm{~cm}^{-1}$ have been assigned as the $\mathrm{S}-\mathrm{O}$ stretching frequencies of the dominating species in liquid dimethyl sulfoxide, evaluated as centrosymmetric dimers with antiparallel polar S-O groups. The shifts of vibrational frequencies and force constants for coordinated dimethyl sulfoxide ligands in hexasolvated trivalent metal ion complexes are discussed. Hexasolvated scandium(III) ions are found in dimethyl sulfoxide solution and in $\left[\mathrm{Sc}\left(\mathrm{OSMe}_{2}\right)_{6}\right] \mathrm{I}_{3}$. The iodide ion-dipole attraction shifts the methyl group $\mathrm{C}-\mathrm{H}$ stretching frequency for $(\mathrm{S}-) \mathrm{C}-\mathrm{H} \cdots \mathrm{I}^{-}$ more than for the intermolecular $(\mathrm{S}-) \mathrm{C}-\mathrm{H} \cdots \mathrm{O}$ interactions in liquid dimethyl sulfoxide.
\end{abstract}

\section{Introduction}

Dimethyl sulfoxide $\left(\mathrm{Me}_{2} \mathrm{SO}\right)$ is a highly associated liquid, ${ }^{1-3}$ with high dipole moment $(\mu=3.96 \mathrm{D})$ and permittivity $(\varepsilon=46.4)$, and is extensively used in organic synthetic work. The high dipole moment is certainly the reason for the local order and the large liquid range (boiling point $462 \mathrm{~K}$ ). X-Ray and neutron diffraction studies, indicate that the intermolecular arrangement in liquid dimethyl sulfoxide close to the melting point (291.7 K) resembles that in the crystal structure, where pairs of dimethyl sulfoxide molecules form "closed ring" dimers with antiparallel dipoles. ${ }^{2,3}$ These dimers are held together by weak $\mathrm{C}-\mathrm{H} \cdots \mathrm{O}$ interactions and electrostatic attraction between the negative oxygen and positive sulfur ends of adjacent dipoles in the crystal

$\dagger$ Electronic supplementary information (ESI) available: Description of the internal and symmetry coordinates of $\left[\mathrm{Sc}\left(\mathrm{OSMe}_{2}\right)_{6}\right]^{3+}$, fundamental vibrations of $\left(\mathrm{CH}_{3}\right)_{2} \mathrm{SO}$ and $\left(\mathrm{CD}_{3}\right)_{2} \mathrm{SO}$ molecules in $0.6 \mathrm{M}$ $\mathrm{CCl}_{4}$ solution, intermolecular interactions from dimethyl sulfoxide crystal structure, EXAFS data for $\left[\mathrm{Sc}\left(\mathrm{OSMe}_{2}\right)_{6}\right]^{3+}$ in dimethyl sulfoxide solution with WinXAS fitted model functions and separate scattering contributions and Fourier transforms with magnitudes and imaginary parts, Raman and IR spectra of deuterated dimethyl sulfoxide and of $\left[\mathrm{Sc}\left(\mathrm{OS}\left(\mathrm{CD}_{3}\right)_{2}\right)_{6}\right] \mathrm{I}_{3}$. See http://www.rsc.org/suppdata/dt/b4/ b413486a/ structure of dimethyl sulfoxide (see Fig. S1 $\dagger$ ). ${ }^{4}$ Theoretical calculations confirm the stability of dimer formation. ${ }^{5}$

Vibrational spectroscopy is a very sensitive method for studying weak $\mathrm{C}-\mathrm{H} \cdots \mathrm{O}$ interactions in condensed phases. Relatively small shifts, decreasing the $\mathrm{C}-\mathrm{H}$ stretching frequency less than $20 \mathrm{~cm}^{-1}$, have been suggested to indicate weak hydrogen bonding. ${ }^{3}$ However, careful interpretations are necessary when vibrational coupling may occur, for example band splitting due to Fermi resonance with overtones, ${ }^{6}$ and for systems with long range electrostatic attractive forces. ${ }^{7}$ In crystal structures geometry criteria based on the atomic arrangement are useful aids in attributing $\mathrm{C}-\mathrm{H} \ldots \mathrm{O}$ interactions as actual hydrogen bonding. ${ }^{7}$ While this is not possible for liquids, the presence of weak hydrogen bonding is important for the solvent properties and for solute-solvent interactions, particularly in biochemical systems. This is reflected in several Lewis basicity scales for solvent molecules based on their ability to accept hydrogen bonds, which are deduced from the effect of hydrogen bond association with a reference acid in solution, inferred from e.g. thermodynamic or spectroscopic data ${ }^{8}$

Ionic compounds are often easily dissolved in dimethyl sulfoxide, and solvates of metal ions are appropriate precursors for many inorganic syntheses. The dimethyl sulfoxide molecule is a strong Lewis base able to form bonds to metal ions 
$\left(\mathrm{M}^{n}+\right)$ via the oxygen atom, and for platinum group metals also via the sulfur atom. However, solvation of the anions via weak $\mathrm{C}-\mathrm{H} \cdots \mathrm{X}^{-}$interactions is also important to form dissociated electrolyte solutions in this aprotic solvent. The $\mathrm{M}-$ $\mathrm{O} / \mathrm{S}$ bonding significantly affects its structure, and the semiweighted mean $\mathrm{S}-\mathrm{O}$ bond distance has been found to increase from 1.492(1) $\AA$ in free sulfoxides to 1.528(1) $\AA$ in O-bonded metal complexes, while $\mathrm{M}-\mathrm{S}$-bonding results in a decrease to $1.474(1) \AA .{ }^{1}$ The $\mathrm{S}-\mathrm{O} \sigma$-bond is highly polarized with positive charge on the sulfur atom and negative on oxygen. ${ }^{1}$ The internal electron redistribution when the dimethyl sulfoxide molecule is coordinated is often described in terms of a partial S-O double bond character and moderate $\pi$-acceptor ability of the $\mathrm{S}-\mathrm{O}$ group. $\mathrm{M}-\mathrm{O}$ bonding reduces the electron density on the oxygen atom, increases the positive charge on sulfur, and decreases the $\pi$-electron backtransfer from oxygen to sulfur. ${ }^{1}$ The modified internal bonding and geometry induce characteristic shifts and changes in the vibrational spectra for complexes with dimethyl sulfoxide ligands, ${ }^{9-12}$ including new metal-ligand bands appearing at frequencies lower than $600 \mathrm{~cm}^{-1} .^{12-16}$

Intense and easily identifiable bands in vibrational spectra are often ascribed to "group" modes, and their shifts used as coordination indicators for functional groups. For dimethyl sulfoxide, in particular the infrared absorption band assigned to $\mathrm{S}-\mathrm{O}$ stretching (at $1102 \mathrm{~cm}^{-1}$ in the gas phase) has been correlated to the $\mathrm{S}-\mathrm{O}$ bond distance, and reported to shift up to $1154 \mathrm{~cm}^{-1}$ and down to $862 \mathrm{~cm}^{-1}$ in $\mathrm{S}$ and $\mathrm{O}$ bonded complexes, respectively. ${ }^{1}$ However, the internal skeletal vibrational modes can interact with the methyl group rocking modes, which may make assignments of normal modes as group frequencies ambiguous, and careful analyses using normal coordinate methods are often necessary for such detailed interpretations of a spectral feature in terms of changes in a specific bond strength. ${ }^{15}$

In the current study normal coordinate analyses of the dimethyl sulfoxide molecule itself and of the hexasolvated Group 3 ion scandium(III) are performed and compared with our previous studies of the hexakis(dimethyl sulfoxide) solvates of the Group 13 ions, aluminium(III), gallium(III), indium(III) and thallium(III). ${ }^{15,16}$ The large Group 3 ions yttrium(III) and lanthanum(III) coordinate eight dimethyl sulfoxide molecules in the solid state and in solution, ${ }^{17,18}$ as do also all the lanthanide(III) ions. A combined EXAFS, crystallographic and vibrational study of the solvated lanthanide(III) ions will be reported separately. ${ }^{19}$

Crystal structures of the compounds $\left[\mathrm{Sc}\left(\mathrm{H}_{2} \mathrm{O}\right)_{6}\right]-$ $\left[\mathrm{Sc}\left(\mathrm{OSO}_{2} \mathrm{CH}_{3}\right)_{6}\right],{ }^{20}\left[\mathrm{Sc}\left(\mathrm{H}_{2} \mathrm{O}\right)_{7}\right]\left[\mathrm{C}\left(\mathrm{CF}_{3} \mathrm{SO}_{2}\right)_{3}\right]_{3} \cdot \mathrm{H}_{2} \mathrm{O},{ }^{21}\left[\mathrm{Sc}\left(\mathrm{H}_{2} \mathrm{O}\right)_{7}\right]$ $\mathrm{X}_{3}(\mathrm{X}=\mathrm{Cl}, \mathrm{Br}),\left[\mathrm{Sc}\left(\mathrm{H}_{2} \mathrm{O}\right)_{7}\right] \quad \mathrm{I}_{3} \cdot \mathrm{H}_{2} \mathrm{O},{ }^{22}$ and $\left[\mathrm{Sc}\left(\mathrm{H}_{2} \mathrm{O}\right)_{8.0}\right]$ $\left(\mathrm{CF}_{3} \mathrm{SO}_{3}\right)_{3},{ }^{23}$ reveal discrete hydrated scandium(III) ions with mean $\mathrm{Sc}-\mathrm{O}$ distances of $2.085,2.16$ and $2.237 \AA$, for six, seven and eight coordinated water molecules, respectively. Evidently, the scandium(III) ion is large enough to accommodate more than six small oxygen-coordinated monodentate ligands, such as water. In crystal structures of dimethyl sulfoxide solvated metal ions, the oxygen-coordinated ligands are frequently disordered with configurations corresponding to a $180^{\circ}$ rotation around the $\mathrm{M}-\mathrm{O}$ bond, giving rise to two partially occupied sulfur atom positions and high displacement parameters for the oxygen and carbon positions. ${ }^{24-27}$ Theoretical calculations show that the photochemical excitation energy required for direct inversion of the pyramidal structure through a planar $C_{2 v}$ transition state is quite high, about $41.5 \mathrm{kcal} \mathrm{mol}^{-1}{ }^{28}$

Crystallographic disorder is particularly common with symmetric cations such as perchlorate, and often frustrates structure determinations or prevents accurate bond distances to be obtained. ${ }^{16,26}$ The $\mathrm{d}^{0}$ scandium(III) ion is, according to Pearson's hard-soft acid-base principles, a "hard" cation. ${ }^{29}$ Therefore, in the current work, as also for aluminium(III), gallium(III), indium(III), ${ }^{15}$ and other trivalent metal ions, ${ }^{17,18}$ the "soft" anion iodide was chosen for the crystallographic studies as it forms weak complexes with "hard" ions, ${ }^{29}$ and does not give rise to additional bands in the vibrational spectra. EXAFS spectroscopy was used to study the structure of the solvated scandium(III) ion in dimethyl sulfoxide solution.

As a basis for reliable force field analyses of dimethyl sulfoxide complexes, a complete assignment of the vibrational normal modes of the dimethyl sulfoxide molecule itself was required. Tranquille et $a l .{ }^{30}$ and Geiseler et $a l .{ }^{31}$ have previously performed normal coordinate analyses of the vibrational spectra of gaseous and liquid dimethyl sulfoxide and its fully deuterated form. Their assignments were however incomplete, as also the computational studies by Allinger et al. ${ }^{5}$ since experimental frequencies below $300 \mathrm{~cm}^{-1}$ were not investigated. Hence, the vibrational spectra of gaseous and liquid dimethyl sulfoxide, including their fully deuterated forms, were reinvestigated and in the current study a full normal coordinate analysis has been performed as a preliminary to the analyses for the hexakis(dimethyl sulfoxide)scandium(III) ion, and other solvates of trivalent metal ions. ${ }^{19}$

\section{Experimental}

\section{Chemicals and sample preparation}

Dimethyl sulfoxide, $\left(\mathrm{CH}_{3}\right)_{2} \mathrm{SO}$ (Merck), was distilled over calcium hydride (Fluka) under vacuum prior to use. Deuterated dimethyl sulfoxide, $\left(\mathrm{CD}_{3}\right)_{2} \mathrm{SO}$ (Merck), of analytical grade was used without further purification. Colourless crystals of X-ray quality with the composition $\left[\mathrm{Sc}\left(\mathrm{OSMe}_{2}\right)_{6}\right] \mathrm{I}_{3}$, were obtained by slowly cooling from $\approx 320 \mathrm{~K}$ to room temperature a saturated solution of anhydrous $\mathrm{ScI}_{3}$ (Aldrich, 99.999\%), heated by the strongly exothermic dissolution reaction.

Anhydrous scandium(III) trifluoromethanesulfonate, $\mathrm{Sc}\left(\mathrm{CF}_{3} \mathrm{SO}_{3}\right)_{3}$, was obtained by dissolving scandium(III) oxide, $\mathrm{Sc}_{2} \mathrm{O}_{3}$ (Johnson Matthey), in aqueous trifluoromethanesulfonic acid, $\mathrm{CF}_{3} \mathrm{SO}_{3} \mathrm{H}$ (Riedel-de-Haën, purum), by heating and stirring, followed by evaporation of the solvent and excess acid in an oven. The remaining hygroscopic white powder was kept at $465 \mathrm{~K}$ to prevent water uptake and hydrolysis. A saturated solution was prepared by dissolving the $\mathrm{Sc}\left(\mathrm{CF}_{3} \mathrm{SO}_{3}\right)_{3}$ salt in dimethyl sulfoxide under dry nitrogen atmosphere. The scandium(III) concentration of the dimethyl sulfoxide solution was determined to be $0.62 \mathrm{~mol} \mathrm{dm}^{-3}$, by EDTA titration and also by cation exchange (Dowex $50 \mathrm{~W}-\mathrm{X} 8, \mathrm{H}^{+}$form) after dilution with water. The density, $1.25 \mathrm{~g} \mathrm{~cm}^{-3}$, was measured with an Anton Paar DMA 35 densitometer.

\section{Single crystal X-ray diffraction}

Intensity data were collected for $\left[\mathrm{Sc}\left(\mathrm{OS}\left(\mathrm{CH}_{3}\right)_{2}\right)_{6}\right] \mathrm{I}_{3}$ at ambient temperature using Mo-K $\alpha$ radiation on a Bruker SMART platform equipped with a CCD area detector (crystal to detector distance $5.00 \mathrm{~cm}$ ) and a graphite monochromator. Cell parameters were refined using 1301 reflections. A hemisphere of data (1291 frames) was collected using the $\omega$-scan method $\left(0.3^{\circ}\right.$ frame width) with each frame exposed $30 \mathrm{~s}$. The first 50 frames were remeasured at the end of the data collection to monitor instrument and crystal stability, and the intensity decay was found to be negligible. Data reduction and empirical absorption correction were performed using the Bruker program packages SAINT and SADABS, respectively. ${ }^{32}$ The structure was solved by direct methods and refined using full-matrix least squares on $F^{2}$ using the SHELXTL program..$^{33}$ Non-hydrogen atoms were treated anisotropically. Hydrogen atoms were added at calculated positions and refined using a riding model.

Crystal structure determination. $\mathrm{C}_{12} \mathrm{H}_{36} \mathrm{~S}_{6} \mathrm{O}_{6} \mathrm{I}_{3} \mathrm{Sc}, \quad M=$ $894.43 \mathrm{~g} \mathrm{~mol}^{-1}$, Space group trigonal $R \overline{3}$ (No. 148), $a=$ 11.1244(13) $\AA, c=23.399(4) \AA, V=2507.7(6) \AA^{3}, T=295(2)$ $\mathrm{K}, Z=3, D_{\mathrm{m}}=1.77(1)$ and $D_{\mathrm{c}}=1.777 \mathrm{~g} \mathrm{~cm}^{-3}, \mu(\mathrm{Mo}-\mathrm{K} \alpha)=$ $3.385 \mathrm{~mm}^{-1}, 4720$ reflections measured, 1318 unique reflections $\left(R_{\text {int }}=0.1068\right), 565$ observed reflections, final $R_{1}=0.0404, w R_{2}=$ 0.0809 and for all data $R_{1}=0.1146, w R_{2}=0.0951$. 
CCDC reference number 249315.

See http://www.rsc.org/suppdata/dt/b4/b413486a/ for crystallographic data in CIF or other electronic format.

\section{X-Ray absorption spectroscopy}

Sc K-edge EXAFS measurements were performed at the wiggler beam line 4-1 at Stanford Synchrotron Radiation Laboratory (SSRL), USA, operating at $3.0 \mathrm{GeV}$ and $70-100 \mathrm{~mA}$. The EXAFS station was equipped with a Si[111] double crystal monochromator and higher order harmonics were reduced by detuning the second crystal to retain $30 \%$ of the maximum intensity at the end of the scan range. The data collection was performed in fluorescence mode with beam path and sample in helium atmosphere to reduce air absorption, using a Lytle detector (nitrogen filled) without filter at ambient temperature. External energy calibration was made with a scandium metal foil and 3-4 scans were averaged giving useable data quality up to $k \approx 15 \AA^{-1}$ for a solution of $\left[\mathrm{Sc}\left(\mathrm{OSMe}_{2}\right)_{6}\right]\left(\mathrm{CF}_{3} \mathrm{SO}_{3}\right)_{3}$ (to avoid fluorescence from iodide). The EXAFS data were evaluated by means of the GNXAS, WinXAS, and EXAFSPAK program packages ( $c f$. Table 1), ${ }^{34-36}$ using standard procedures for pre-edge subtraction, normalization and spline removal of background. The FEFF 8.2 program $^{37}$ was used in conjunction with the WinXAS and EXAFSPAK programs, to select the predominating scattering pathways around the scandium atom $(<\approx 5 \AA)$ and calculate their phase and amplitude backscattering parameters for modeling the $\left[\mathrm{Sc}\left(\mathrm{OS}\left(\mathrm{CH}_{3}\right)_{2}\right)_{6}\right]^{3+}$ complex, using the atomic coordinates from the $\left[\mathrm{Sc}\left(\mathrm{OSMe}_{2}\right)_{6}\right] \mathrm{I}_{3}$ crystal structure. The GNXAS package integrates multiple-scattering calculations associated with two, three, and four atom configurations with a rigorous fitting procedure of the raw experimental EXAFS data. ${ }^{36}$

\section{Vibrational spectra}

Mid-IR (200-4000 $\mathrm{cm}^{-1}$, resolution $4 \mathrm{~cm}^{-1}, 128$ scans) absorption spectra were recorded in purged atmosphere using a BioRad (Digilab) FTS 175 spectrometer with a CsI beamsplitter. Far-infrared spectra $\left(50-700 \mathrm{~cm}^{-1}\right.$, resolution $\left.4 \mathrm{~cm}^{-1}\right)$ were recorded with a Bio-Rad (Digilab) FTS-40 spectrometer with a wire-mesh beamsplitter. Sample cells with silicon windows were used for the liquids. Pellets were prepared of the solid sample, diluted with caesium iodide for mid-IR and polyethylene for far-IR. Raman spectra of the liquid samples were recorded on a dedicated Bio-Rad FT-Raman spectrometer with an Adlas DTY-321 Nd-YAG-laser (1024 nm, $150 \mathrm{~mW})$, whereas for the pure solid a Renishaw System 1000 spectrometer was used, equipped with a Leica DMLM microscope, a $20 \mathrm{~mW}$ diode laser $(782 \mathrm{~nm})$ and a Peltier-cooled CCD detector. All measurements were performed at ambient temperature. Vibrational data for gaseous dimethyl sulfoxide were obtained from the literature. ${ }^{30,31}$

\section{Force field analysis}

The dimethyl sulfoxide molecule was described in the $C_{\mathrm{s}}$ point group. Of the 24 fundamental normal modes 13 belong to the $\mathrm{A}^{\prime}$ symmetry species, while the remaining 11 of $\mathrm{A}^{\prime \prime}$ symmetry do not preserve the mirror plane. The $\left[\mathrm{Sc}\left(\mathrm{OS}\left(\mathrm{CH}_{3}\right)_{2}\right)_{6}\right]^{3+}$ complex generates 177 fundamental vibrational modes, including 108 modes (also methyl torsions) belonging to the 12 methyl groups, and the complexity made some simplifications necessary for the normal coordinate analysis. Therefore, the methyl groups were treated as point masses. As the first step of the force field analysis a monosolvated species, $\mathrm{ScOSMe}$, was considered in $C_{\mathrm{s}}$ symmetry. In the final step, a full normal-coordinate calculation was performed with the $\left[\mathrm{Sc}\left(\mathrm{OSMe}_{2}\right)_{6}\right]^{3+}$ complex described in the $S_{6}$ point group. Even with point masses introduced for the methyl groups, 69 normal modes remain.

Wilson's GF matrix method was used for the calculation of vibrational frequencies using a symmetrized valence force field.
For the dimethyl sulfoxide molecule the initial force constants were partly adopted from previous work, ${ }^{30,31}$ and refined to give a satisfactory fit of calculated and observed frequencies, Tables 2 , 3. The force constants obtained provided start values for the analysis of the spectra of the $\left[\mathrm{Sc}\left(\mathrm{OSMe}_{2}\right)_{6}\right]^{3+}$ complex. The PCbased program package developed by J. Mink and L. Mink was used for the calculations. ${ }^{38}$

\section{Results}

\section{Crystal structure of $\left[\mathrm{Sc}\left(\mathrm{OSMe}_{2}\right)_{6}\right] \mathrm{I}_{3}$}

The $\left[\mathrm{Sc}\left(\mathrm{OSMe}_{2}\right)_{6}\right] \mathrm{I}_{3}$ compound is isomorphous with the hexakis(dimethyl sulfoxide)-aluminium(III), -gallium(III) and -indium(III) iodides, which all crystallize in the trigonal space group $R \overline{3}$ (No. 148). ${ }^{15}$ The crystal structure comprises discrete hexakis(dimethyl sulfoxide)scandium(III) complexes (Fig. 1) and iodide ions. The scandium ion in a site of $\overline{3}$ symmetry is octahedrally surrounded by six oxygen atoms with the $\mathrm{Sc}-\mathrm{O}$ bond distance $2.069(3) \AA$ and the $\mathrm{O}-\mathrm{Sc}-\mathrm{O}$ angle $92.00(15)^{\circ}$ in the $\left[\mathrm{Sc}(\mathrm{OSMe})_{6}\right]^{3+}$ complex. The $\mathrm{S}-\mathrm{O}$ distance of the dimethyl sulfoxide ligands is 1.536(4) $\AA$, and the $\mathrm{Sc}-\mathrm{O}-\mathrm{S}$ angle $132.6(2)^{\circ}$. No disorder, which often is associated with dimethyl sulfoxide complexes, was detected. All methyl hydrogen atoms of the dimethyl sulfoxide ligands are in contact with the surrounding iodide ions with $\mathrm{C}(-\mathrm{H}) \cdots \mathrm{I}^{-}$distances between 3.98 and $4.33 \AA$ ( $\mathrm{I}^{-} \ldots \mathrm{H}$ distances between 3.11 and $3.39 \AA$ for $\mathrm{C}-\mathrm{H} 0.96 \AA$ ).

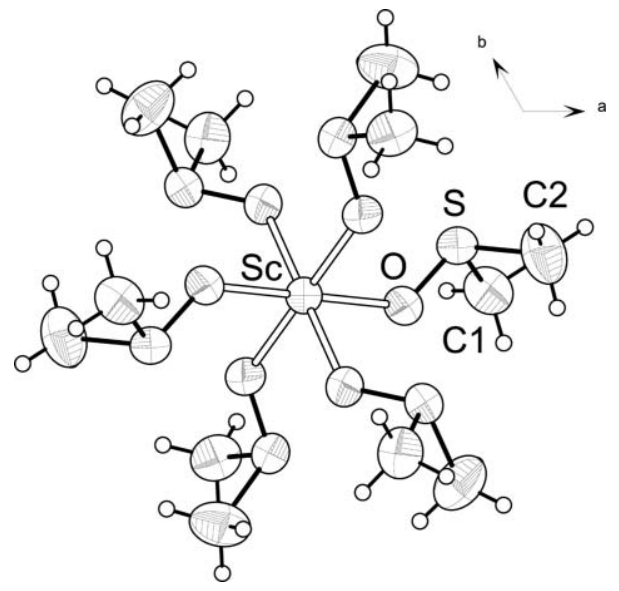

Fig. 1 The $\mathrm{Sc}\left(\mathrm{OS}\left(\mathrm{CH}_{3}\right)_{2}\right)_{6}{ }^{3+}$ complex projected along the $\overline{3}$ axis parallel to $c$, with $50 \%$ probability thermal ellipsoids for non-hydrogen atoms. Selected distances $(\AA)$ : Sc-O, 2.069(3), S-O 1.536(4), S-C1 1.754(5), $\mathrm{S}-\mathrm{C} 21.773(6)$, Sc ‥S 3.308(2), and Sc-O-S angle $132.6(2)^{\circ}$.

\section{EXAFS spectroscopy}

The $k^{3}$-weighted Sc K-edge EXAFS oscillation and the corresponding Fourier transform for the $0.62 \mathrm{~mol} \mathrm{dm}^{-3}$ solution of scandium(III) trifluoromethanesulfonate in dimethyl sulfoxide are shown in Fig. 2. The analyses show that the main components in the EXAFS spectra are the single backscattering pathways from the oxygen and sulfur atoms, with significant contributions from three-leg Sc-O-S, and four-leg linear Sc$\mathrm{O}-\mathrm{Sc}-\mathrm{O}$ multiple scattering pathways within the $\mathrm{ScO}_{6}$ core (Fig. $\mathrm{S} 2 \dagger$ ). The corresponding peaks in the Fourier transforms (uncorrected for phase shift) appear at (a) $1.6 \AA$ (Sc-O), (b) $3.0 \AA(\mathrm{Sc} \cdots \mathrm{S}+\mathrm{Sc}-\mathrm{O}-\mathrm{S})$ and $(\mathrm{c}) 3.4 \AA(\mathrm{Sc}-\mathrm{O}-\mathrm{Sc}-\mathrm{O}), c f$. Fig. 2. The mean distances obtained by $k$-space fitting on the unfiltered data are Sc-O 2.09(1) $\AA$ and Sc ..S 3.34(2) $\AA$, for six dimethyl sulfoxide ligands. The estimated errors (within brackets) include not only the statistical noise (cf. Table 1), but also contributions from variations in the results from the data treatment procedures in the different program systems, energy calibration errors, absorption effects, etc. The refined EXAFS model parameters summarized in Table 1 for the three different 

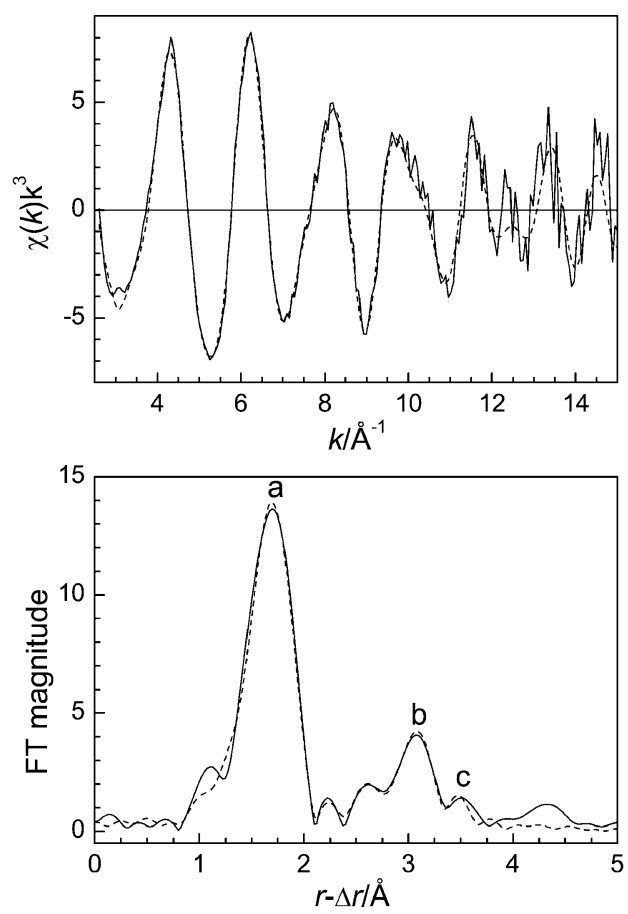

Fig. 2 EXAFS $k^{3}$-weighted experimental scandium K-edge data and Fourier transforms of the $0.62 \mathrm{~mol} \mathrm{dm}^{-3}$ scandium(III) trifluoromethanesulfonate dimethyl sulfoxide solution (solid lines), with fitted model functions (dashed lines, fitted with WinXAS), with parameters according to Table 1. For separate contributions, see Fig S2.†

data treatment packages, with standard deviations estimated only from the statistical noise level, reassuringly showed similar coordination distances. The coordination number was held constant at six, and the amplitude reduction factor, $S_{0}^{2}$, was refined to reasonable values for WinXAS and EXAFSPAK, Table 1. Double electron excitations, which may affect the $S_{0}^{2}$ value, occur at 4539.4 and $4680.3 \mathrm{eV}$ after the scandium K-edge but are not intense. Only a minor feature is visible in Fig. 2 at about $k=3 \AA^{-1}$. However, the mean square displacement parameters $\left(\sigma^{2}\right)$ in the Debye-Waller factors differ with the three program packages, and probably contain accumulated errors from spline and background subtraction procedures, and from the modeling of multiple scattering. The fit of the model function is displayed in Fig. 2 with separate contributions from the scattering pathways visualized in Fig. S2a. $\dagger$

\section{Vibrational spectra of dimethyl sulfoxide}

The remeasured vibrational spectra of liquid dimethyl sulfoxide (Figs. 3, 4, S3, S4 $\dagger$ ), including the far-infrared region, were analysed by normal coordinate methods to obtain a force field that could be adapted to dimethyl sulfoxide solvates with metal ions. For the $\left(\mathrm{CH}_{3}\right)_{2} \mathrm{SO}$ molecule, 9 polarized Raman bands out of 13 possible were observed and assigned to the totally symmetric $\mathrm{A}^{\prime}$ species in the $C_{\mathrm{s}}$ point group, including $v_{5}$ and $v_{12}$ (Table 2) with depolarization ratios around 0.7 . For the deuterated liquid only 7 polarized Raman bands were observed, Table 3 . The methyl groups are equivalent, and the weak vibrational coupling preserves the $C_{\mathrm{s}}$ local symmetry for a number of vibrational modes, which explains the reduced number of observable fundamental bands. Experimentally, only two major features are immediately apparent in the $\mathrm{C}-\mathrm{H}$ and C-D stretching regions, but for the degenerate higher frequency band some splitting could be discerned in the infrared spectra $\left(v_{1}\right.$ and $\left.v_{2}\right)$.

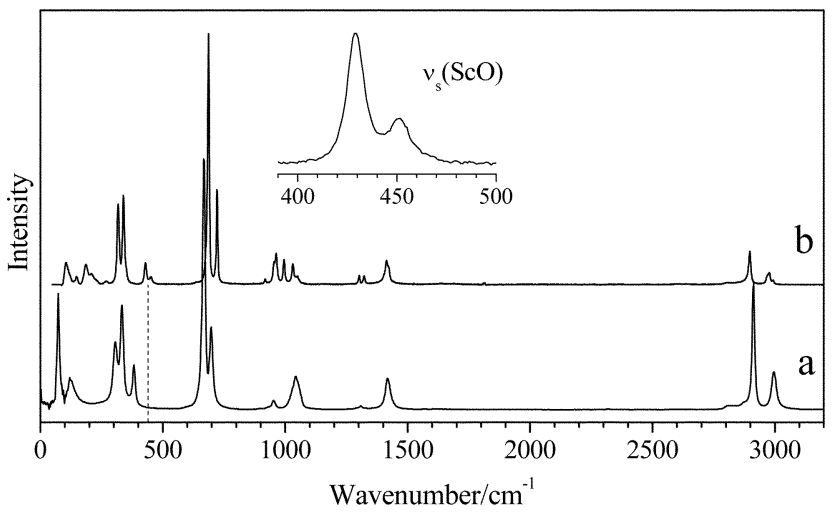

Fig. 3 Raman spectra of (a) $\left(\mathrm{CH}_{3}\right)_{2} \mathrm{SO}$ and (b) $\left[\mathrm{Sc}\left(\mathrm{OS}\left(\mathrm{CH}_{3}\right)_{2}\right)_{6}\right] \mathrm{I}_{3}$.

The methyl in-phase $\left(\mathrm{A}^{\prime}\right)$ and out-of-phase $\left(\mathrm{A}^{\prime \prime}\right)$ symmetric stretching modes are expected at the same wavenumber in the IR and Raman spectra ( $v_{3}$ and $v_{16}$ ) of liquid dimethyl sulfoxide. The asymmetric depolarized modes also coincide, and at most three bands could be assigned to the four modes expected, $v_{4}, v_{5}$, $v_{17}$ and $v_{18}$. The symmetric deformations $\left(v_{6}\right.$ and $v_{19}$ ) of the methyl group showed no strong interaction with other modes and only two bands are observed in the usual range near $1300 \mathrm{~cm}^{-1}$.

The most characteristic vibrational modes are those dominated by S-O stretching. IR frequencies at $1043 \mathrm{~cm}^{-1}$ for solid $\left(213 \mathrm{~K}\right.$ ) dimethyl sulfoxide, $1058 \mathrm{~cm}^{-1}$ for liquid (300 K), and $1101 \mathrm{~cm}^{-1}$ for gas $(360 \mathrm{~K})$, have been reported for this band, ${ }^{1}$ while the asymmetric Raman band for the liquid has been deconvoluted into several components ascribed to different associated molecular species. ${ }^{39-42}$ Reliable assignment of the $\mathrm{S}-\mathrm{O}$ stretching mode is important, as it is widely used to diagnose complex formation, and the position and interpretation of the $\mathrm{S}-\mathrm{O}$ stretching frequencies have been discussed at length in the literature. ${ }^{1}$

Table 1 Scandium K-edge EXAFS model fitting results for the $\left[\mathrm{Sc}\left(\mathrm{OSMe}_{2}\right)_{6}\right]^{3+}$ complex in dimethyl sulfoxide solution ${ }^{a}$

\begin{tabular}{lrlllll}
\hline Pathway & $n$ & $r / \AA$ & $\sigma^{2} / \AA^{2}$ & $E_{0} / \mathrm{eV}$ & $k$ range & Program \\
\hline $\mathrm{Sc}-\mathrm{O}^{b}$ & 6 & $2.093(3)$ & $0.0016(2)$ & $4505.0(5)$ & $3.7-15.0$ & GNXAS $^{36}$ \\
$\mathrm{~S}-\mathrm{O}$ & 6 & $1.535(5)$ & $0.0014(3)$ & & & \\
$\mathrm{Sc}-\mathrm{S}^{d}$ & 6 & $3.374(10)^{d}$ & & & \\
$\mathrm{Sc}-\mathrm{O}$ & 6 & $2.090(5)$ & $0.0027(3)$ & $4500.1(6)$ & $4.0-14.0$ & EXAFSPAK $^{35}$ \\
$\mathrm{Sc} \cdots \mathrm{S}$ & 6 & $3.351(9)$ & $0.0048(8)$ & & & \\
$\mathrm{Sc}-\mathrm{O}-\mathrm{S}^{c}$ & 12 & $3.501(12)$ & $0.003(1)$ & & & \\
$\mathrm{Sc}-\mathrm{O}-\mathrm{O}^{c}$ & 12 & $4.22(4)$ & $0.008(5)$ & & & WinXAS $^{34}$ \\
$\mathrm{Sc}-\mathrm{O}$ & 6 & $2.088(4)$ & $0.0046(3)$ & $4503.4(5)$ & $2.6-15.0$ & \\
$\mathrm{Sc} \cdots \mathrm{S}$ & 6 & $3.303(6)$ & $0.0080(6)$ & & & \\
$\mathrm{Sc}-\mathrm{O}-\mathrm{S}^{c}$ & 12 & $3.467(10)$ & $0.0022(6)$ & & & \\
$\mathrm{Sc}-\mathrm{O}-\mathrm{Sc}-\mathrm{O}^{c}$ & $3 \times 6$ & $4.12(2)$ & $0.009(2)$ & & &
\end{tabular}

${ }^{a}$ Parameters: $n$ frequency (fixed), $r$ mean backscattering distance (= half of pathway), $\sigma^{2}$ mean square displacement. The standard deviations given here within brackets are derived only from the statistical noise in the data. The amplitude reduction factor $S_{0}^{2}=0.96$ (WinXAS), 0.91 (EXAFSPAK) and 1.0 (GNXAS). ${ }^{b}$ Includes multiple scattering in the $\mathrm{ScO}_{6}$ core for which the $\mathrm{O}-\mathrm{Sc}-\mathrm{O}$ angle has been determined to be $180.0(2)^{\circ}$. ${ }^{c} \mathrm{Multiple}$ scattering pathway. ${ }^{d}$ Obtained from the refined $\mathrm{Sc}-\mathrm{O}$ and $\mathrm{S}-\mathrm{O}$ bond distances and $\mathrm{Sc}-\mathrm{O}-\mathrm{S}$ angle $136.3(5)^{\circ}$. 
Table 2 Observed and calculated fundamental vibrational frequencies, $v\left(\mathrm{~cm}^{-1}\right)$, for gaseous and liquid $\left(\mathrm{CH}_{3}\right)_{2} \mathrm{SO}^{a}$

\begin{tabular}{|c|c|c|c|c|c|c|c|c|c|}
\hline & & $\left(\mathrm{CH}_{3}\right)$ & O, $\operatorname{gas}^{b}$ & $\left(\mathrm{CH}_{3}\right)_{2} \mathrm{SO}, \mathrm{li}$ & & & & & \\
\hline & & IR & Calc. & $\mathrm{IR}^{c}$ & $\operatorname{Raman}^{c}$ & & Calc. ${ }^{c}$ & & \\
\hline & & $v_{\text {obs }}$ & $v_{\mathrm{NCA}}$ & $v_{\text {obs }}$ & $v_{\text {obs }}$ & $\rho_{\text {pol }}$ & $v_{\mathrm{NCA}}$ & Potential energy distribution $^{d}$ & Assignment \\
\hline $\mathrm{A}^{\prime}$ & $v_{1}$ & 3010 & 3010 & $2991(4)$ & $2996(23)$ & 0.75 & 2998 & $95 v_{\mathrm{a}}\left(\mathrm{CH}_{3}\right)$ & $v_{\mathrm{a}}\left(\mathrm{CH}_{3}\right)$ \\
\hline & $v_{2}$ & 3010 & 3008 & $2983(4)$ & - & - & 2997 & $95 v_{\mathrm{a}}^{\prime}\left(\mathrm{CH}_{3}\right)$ & $v_{\mathrm{a}}^{\prime}\left(\mathrm{CH}_{3}\right)$ \\
\hline & $v_{3}$ & 2933 & 2938 & $2905(3)$ & $2913(42)$ & 0.04 & 2920 & $100 v_{\mathrm{s}}\left(\mathrm{CH}_{3}\right)$ & $v_{\mathrm{s}}\left(\mathrm{CH}_{3}\right)$ \\
\hline & $v_{4}$ & 1419 & 1420 & $1437(4)$ & - & - & 1436 & $82 \delta_{\mathrm{a}}\left(\mathrm{CH}_{3}\right), 15 \rho^{\prime}\left(\mathrm{CH}_{3}\right)$ & $\delta_{\mathrm{a}}\left(\mathrm{CH}_{3}\right)$ \\
\hline & $v_{5}$ & 1405 & 1413 & $1419(3)$ & $1418(8)$ & 0.70 & 1413 & $83 \delta_{\mathrm{a}}{ }^{\prime}\left(\mathrm{CH}_{3}\right), 15 \rho\left(\mathrm{CH}_{3}\right)$ & $\delta_{\mathrm{a}}{ }^{\prime}\left(\mathrm{CH}_{3}\right)$ \\
\hline & $v_{6}$ & 1304 & 1313 & $1311(2)$ & $1308(2)$ & 0.41 & 1310 & $92 \delta_{\mathrm{s}}\left(\mathrm{CH}_{3}\right)$ & $\delta_{\mathrm{s}}\left(\mathrm{CH}_{3}\right)$ \\
\hline & $v_{7}$ & 1102 & 1114 & $1070(100)^{a}$ & $1067(2)$ & 0.28 & 1075 & $42 v(\mathrm{SO}), 32 \rho^{\prime}\left(\mathrm{CH}_{3}\right), 6 \delta_{\mathrm{a}}\left(\mathrm{CH}_{3}\right)$ & $v(\mathrm{SO})+\rho^{\prime}\left(\mathrm{CH}_{3}\right)$ \\
\hline & $v_{8}$ & 1016 & 1022 & $1032(43)$ & $1029(5)$ & 0.17 & 1024 & $60 \rho\left(\mathrm{CH}_{3}\right), 15 \rho^{\prime}\left(\mathrm{CH}_{3}\right), 12 \delta_{\mathrm{a}}\left(\mathrm{CH}_{3}\right)$ & $\rho\left(\mathrm{CH}_{3}\right)$ \\
\hline & $v_{9}$ & 953 & 938 & $957(5)$ & $957(4)$ & 0.42 & 925 & $42 v(\mathrm{SO}), 33 \rho^{\prime}\left(\mathrm{CH}_{3}\right), 11 \rho\left(\mathrm{CH}_{3}\right)$ & $v(\mathrm{SO})+\rho^{\prime}\left(\mathrm{CH}_{3}\right)$ \\
\hline & $v_{10}$ & 672 & 669 & $670(1)$ & $668(100)^{a}$ & 0.11 & 669 & $75 v_{\mathrm{s}}\left(\mathrm{SC}_{2}\right), 10 \delta\left(\mathrm{SC}_{2}\right), 8 \omega\left(\mathrm{SC}_{2}\right)$ & $v_{\mathrm{s}}\left(\mathrm{SC}_{2}\right)$ \\
\hline & $v_{11}$ & 382 & 384 & $383(2)$ & $382(15)$ & 0.36 & 385 & $84 \delta\left(\mathrm{SC}_{2}\right), 9 \omega\left(\mathrm{SC}_{2}\right)$ & $\delta\left(\mathrm{SC}_{2}\right)$ \\
\hline & $v_{12}$ & 308 & 298 & 307 (1) & $306(34)$ & 0.70 & 297 & $66 \omega\left(\mathrm{SC}_{2}\right), 14 \delta\left(\mathrm{SC}_{2}\right), 9 v_{\mathrm{s}}\left(\mathrm{SC}_{2}\right)$ & $\omega\left(\mathrm{SC}_{2}\right)$ \\
\hline & $v_{13}$ & 102 & 104 & $157(0.2)$ & - & - & 159 & 98 tors $\left(\mathrm{CH}_{3}\right)$ & tors $\left(\mathrm{CH}_{3}\right)$ \\
\hline $\mathrm{A}^{\prime \prime}$ & $v_{14}$ & 3010 & 3007 & $2991(4)$ & $2996(23)$ & 0.75 & 2996 & $52 v_{\mathrm{a}}\left(\mathrm{CH}_{3}\right), 48 v_{\mathrm{a}}^{\prime}\left(\mathrm{CH}_{3}\right)$ & $v_{\mathrm{a}}\left(\mathrm{CH}_{3}\right)$ \\
\hline & $v_{15}$ & 3010 & 2990 & $2983(4)$ & - & - & 2978 & $52 v_{\mathrm{a}}^{\prime}\left(\mathrm{CH}_{3}\right), 48 v_{\mathrm{a}}\left(\mathrm{CH}_{3}\right)$ & $v_{\mathrm{a}}{ }^{\prime}\left(\mathrm{CH}_{3}\right)$ \\
\hline & $v_{16}$ & 2933 & 2938 & $2905(3)$ & $2913(42)$ & 0.04 & 2920 & $100 v_{\mathrm{s}}\left(\mathrm{CH}_{3}\right)$ & $v_{\mathrm{s}}\left(\mathrm{CH}_{3}\right)$ \\
\hline & $v_{17}$ & 1420 & 1417 & $1419(3)$ & $1418(8)$ & 0.75 & 1425 & $46 \delta_{\mathrm{a}}\left(\mathrm{CH}_{3}\right), 36 \delta_{\mathrm{a}}{ }^{\prime}\left(\mathrm{CH}_{3}\right), 8 \rho\left(\mathrm{CH}_{3}\right), 7 \rho^{\prime}\left(\mathrm{CH}_{3}\right)$ & $\delta_{\mathrm{a}}\left(\mathrm{CH}_{3}\right)$ \\
\hline & $v_{18}$ & 1407 & 1380 & $1406(3)$ & - & - & 1390 & $49 \delta_{\mathrm{a}}{ }^{\prime}\left(\mathrm{CH}_{3}\right), 41 \delta_{\mathrm{a}}\left(\mathrm{CH}_{3}\right)$ & $\delta_{\mathrm{a}}{ }^{\prime}\left(\mathrm{CH}_{3}\right)$ \\
\hline & $v_{19}$ & 1319 & 1317 & $1294 \mathrm{sh}$ & $1290 \mathrm{sh}$ & - & 1302 & $92 \delta_{\mathrm{s}}\left(\mathrm{CH}_{3}\right)$ & $\delta_{\mathrm{s}}\left(\mathrm{CH}_{3}\right)$ \\
\hline & $v_{20}$ & 1056 & 1047 & $1032(33)$ & $1029(5)$ & 0.28 & 1041 & $71 \rho\left(\mathrm{CH}_{3}\right), 10 \rho^{\prime}\left(\mathrm{CH}_{3}\right), 10 \delta_{\mathrm{a}}\left(\mathrm{CH}_{3}\right)$ & $\rho\left(\mathrm{CH}_{3}\right)$ \\
\hline & $v_{21}$ & 1021 & 1002 & $1012(29)$ & $1010(3)$ & 0.17 & 999 & $69 \rho^{\prime}\left(\mathrm{CH}_{3}\right), 17 \tau\left(\mathrm{SC}_{2}\right), 9 \rho\left(\mathrm{CH}_{3}\right)$ & $\rho^{\prime}\left(\mathrm{CH}_{3}\right)$ \\
\hline & $v_{22}$ & 695 & 692 & $700(8)$ & $698(26)$ & 0.75 & 700 & $76 v_{\mathrm{a}}\left(\mathrm{SC}_{2}\right), 10 \delta_{\mathrm{a}}\left(\mathrm{CH}_{3}\right), 6 \rho\left(\mathrm{CH}_{3}\right)$ & $v_{\mathrm{a}}\left(\mathrm{SC}_{2}\right)$ \\
\hline & $v_{23}$ & 333 & 333 & $335(3)$ & $322(43)$ & 0.75 & 334 & $84 \tau\left(\mathrm{SC}_{2}\right), 14 v_{\mathrm{a}}\left(\mathrm{SC}_{2}\right)$ & $\tau\left(\mathrm{SC}_{2}\right)$ \\
\hline & $v_{24}$ & 102 & 103 & $157(0.1)$ & - & - & 152 & $98 \operatorname{tors}\left(\mathrm{CH}_{3}\right)$ & tors $\left(\mathrm{CH}_{3}\right)$ \\
\hline
\end{tabular}

${ }^{a}$ Raman and IR frequencies are given for the fundamentals of the monomeric $\left(\mathrm{CH}_{3}\right)_{2} \mathrm{SO}$ species without strong intermolecular interactions (for a more detailed account of the bands in the $\mathrm{S}-\mathrm{O}$ stretching region, see the text and Table 4). ${ }^{b}$ From ref. $30^{c}$ Relative intensities (in brackets) are given relative to the strongest IR band at $1063 \mathrm{~cm}^{-1}$ (for dimers, see Table 4) and Raman band at $668 \mathrm{~cm}^{-1}$; $\rho_{\text {pol }}-$ depolarization ratio; notations of the normal vibrations: $v_{\mathrm{a}}\left(v_{\mathrm{a}}{ }^{\prime}\right), \delta_{\mathrm{a}}\left(\delta_{\mathrm{a}}{ }^{\prime}\right)$ and $\rho\left(\rho^{\prime}\right)$ are the stretching, bending and rocking pairs of modes of $\mathrm{CH}_{3}$ groups, respectively, with dipole changes parallel (perpendicular) to the plane of symmetry; $\delta_{\mathrm{s}}\left(\mathrm{CH}_{3}\right)$ umbrella modes, $v_{\mathrm{s}}$-symmetric $\mathrm{CH}_{3}$ stretch; $v_{\mathrm{s}}\left(\mathrm{SC}_{2}\right)$ and $v_{\mathrm{a}}\left(\mathrm{SC}_{2}\right)$-symmetric and asymmetric $\mathrm{SC}_{2}$ stretch; $\delta\left(\mathrm{SC}_{2}\right), \omega\left(\mathrm{SC}_{2}\right)$ and $\tau\left(\mathrm{SC}_{2}\right)$-scissoring, wagging and twisting $\mathrm{SC}_{2}$ vibrations, respectively; tors-torsional modes. ${ }^{d}$ From normal coordinate analysis, NCA. The numbers denote the relative contributions of the individual modes.
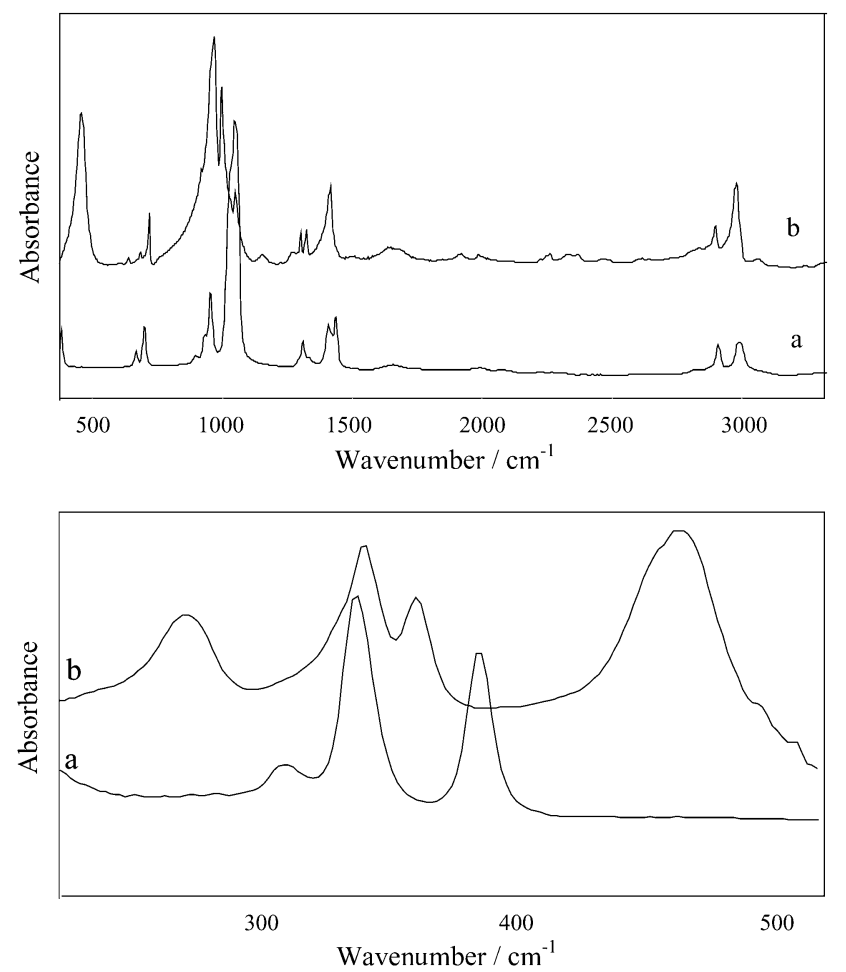

Fig. 4 Infrared absorption spectra of (a) $\left(\mathrm{CH}_{3}\right)_{2} \mathrm{SO}$ and (b) $\left[\mathrm{Sc}\left(\mathrm{OS}\left(\mathrm{CH}_{3}\right)_{2}\right)_{6}\right] \mathrm{I}_{3}$.

For neat liquid dimethyl sulfoxide, $\left(\mathrm{CH}_{3}\right)_{2} \mathrm{SO}$, four infrared and five well-defined Raman bands could be detected in the SO stretching range (1000-1070 $\mathrm{cm}^{-1}$, see Table 4). Four of the
Raman features are in good agreement with those reported by Gill et al.,$^{40}$ and Sastry et al. ${ }^{41}$ This spectral range, which contains several very closely spaced bands, should be analysed by either second derivative $e^{40}$ or Gaussian curve fitting ${ }^{41}$ to obtain reliable positions for the overlapping components.

The strongest Raman band at $1044 \mathrm{~cm}^{-1}$ has been ascribed to a "closed-ring" dimeric structure of two dimethyl sulfoxide molecules with antiparallel S-O dipoles. ${ }^{40,41}$ If the IR band at $1063 \mathrm{~cm}^{-1}$ is assigned as an in-phase SO stretching vibration of this centrosymmetric dimeric species, then an IR band attributed to the out-of-phase mode should be obtained at different frequency. The strongest IR absorption band at $1063 \mathrm{~cm}^{-1}$ is the best candidate for this interpretation. This pair of bands (Raman 1044 and IR $1063 \mathrm{~cm}^{-1}$ ) would then represent the dominating species in liquid dimethyl sulfoxide, expected to consist mostly of dimers with antiparallel SO groups, as indicated by e.g. X-ray diffraction results. ${ }^{2}$ The relative intensity of the Raman band at $1044 \mathrm{~cm}^{-1}$ strongly decreases and its position shifts toward higher wavenumbers in dilute $\mathrm{CCl}_{4}$ solution (Table 4), indicating a structural rearrangement with only weak interactions remaining between 'monomeric' dimethyl sulfoxide molecules.

The assignment of the depolarized $1058 \mathrm{~cm}^{-1}$ Raman and $1048 \mathrm{~cm}^{-1}$ IR bands (Table 4) is still not clear. Different assignments like linear associated species ${ }^{40}$ or asymmetric $\mathrm{S}_{-}$ $\mathrm{O}$ stretchings of the cyclic dimer ${ }^{41}$ have been suggested for the $1058 \mathrm{~cm}^{-1}$ band in the literature. Strictly, such modes should be Raman forbidden and to obtain further information IR absorption and Raman measurements were performed on a $0.6 \mathrm{~mol} \mathrm{dm}^{-3}$ dimethyl sulfoxide solution in $\mathrm{CCl}_{4}$ (Table 4). The presence of IR bands at $1041-1048 \mathrm{~cm}^{-1}$ in neat $\left(\mathrm{CD}_{3}\right)_{2} \mathrm{SO}$ and in neat and dilute $\left(\mathrm{CH}_{3}\right)_{2} \mathrm{SO}$ solution, indicates that there are several types of weak interaction (Table 4). Our experimentally observed IR and Raman frequencies for the $0.6 \mathrm{~mol} \mathrm{dm}^{-3}$ 
Table 3 Observed and calculated fundamental vibrational frequencies, $v\left(\mathrm{~cm}^{-1}\right)$, for gaseous and liquid $\left(\mathrm{CD}_{3}\right)_{2} \mathrm{SO}^{a}$

\begin{tabular}{|c|c|c|c|c|c|c|c|c|c|}
\hline & & \multicolumn{2}{|c|}{$\left(\mathrm{CD}_{3}\right)_{2} \mathrm{SO}, \mathrm{gas}^{b}$} & \multicolumn{4}{|c|}{$\left(\mathrm{CD}_{3}\right)_{2} \mathrm{SO}$, liquid } & \multirow[b]{3}{*}{ Potential energy distribution } & \multirow[b]{3}{*}{ Assignment } \\
\hline & & IR & Calc. $^{d}$ & $\mathrm{IR}^{c}$ & $\operatorname{Raman}^{c}$ & & Calc. $^{d}$ & & \\
\hline \multicolumn{2}{|c|}{$\begin{array}{l}\text { Symmetry } \\
\text { species }\end{array}$} & $v_{\mathrm{obs}}$ & $v_{\mathrm{NCA}}$ & $v_{\mathrm{obs}}$ & $v_{\mathrm{obs}}$ & $\rho$ & $v_{\mathrm{NCA}}$ & & \\
\hline \multirow[t]{13}{*}{$\mathrm{A}^{\prime}$} & $v_{1}$ & 2253 & 2257 & $2251(12)$ & $2250(22)$ & 0.77 & 2249 & $93 v_{\mathrm{a}}\left(\mathrm{CD}_{3}\right)$ & $v_{\mathrm{a}}\left(\mathrm{CD}_{3}\right)$ \\
\hline & $v_{2}$ & 2253 & 2253 & $2242 \mathrm{sh}$ & - & - & 2244 & $94 v_{\mathrm{a}}^{\prime}\left(\mathrm{CD}_{3}\right)$ & $v_{\mathrm{a}}{ }^{\prime}\left(\mathrm{CD}_{3}\right)$ \\
\hline & $v_{3}$ & 2132 & 2118 & $2124(6)$ & $2125(100)$ & 0.03 & 2106 & $98 v_{\mathrm{s}}\left(\mathrm{CD}_{3}\right)$ & $v_{\mathrm{s}}\left(\mathrm{CD}_{3}\right)$ \\
\hline & $v_{4}$ & 1025 & 1011 & $1025(100)$ & $1028(29)$ & 0.75 & 1010 & $81 \delta_{\mathrm{a}}\left(\mathrm{CD}_{3}\right)$ & $\delta_{\mathrm{a}}\left(\mathrm{CD}_{3}\right)$ \\
\hline & $v_{5}$ & 1015 & 1009 & $997 \mathrm{sh}$ & $986 \mathrm{sh}$ & 0.15 & 975 & $82 \delta_{\mathrm{a}}{ }^{\prime}\left(\mathrm{CD}_{3}\right), 9 \rho\left(\mathrm{CD}_{3}\right)$ & $\delta_{\mathrm{a}}{ }^{\prime}\left(\mathrm{CD}_{3}\right)$ \\
\hline & $v_{6}$ & 1043 & 1025 & $1012(92)$ & $1007(24)$ & 0.15 & 1034 & $60 \delta_{\mathrm{s}}\left(\mathrm{CD}_{3}\right), 20 v(\mathrm{SO}), 7 \rho^{\prime}\left(\mathrm{CD}_{3}\right), 6 v_{\mathrm{s}}\left(\mathrm{SC}_{2}\right)$ & $\delta_{\mathrm{s}}\left(\mathrm{CD}_{3}\right)$ \\
\hline & $v_{7}$ & 1096 & 1093 & $1053(100)^{a}$ & $1061(5)^{a}$ & 0.42 & 1082 & $49 v(\mathrm{SO}), 17 \delta_{\mathrm{s}}\left(\mathrm{CD}_{3}\right), 15 v_{\mathrm{s}}\left(\mathrm{SC}_{2}\right), 10 \rho^{\prime}\left(\mathrm{CD}_{3}\right)$ & $v(\mathrm{SO})$ \\
\hline & $v_{8}$ & 814 & 813 & $825(36)$ & $821(1)$ & 0.54 & 815 & $47 \rho\left(\mathrm{CD}_{3}\right), 15 \rho^{\prime}\left(\mathrm{CD}_{3}\right), 12 \delta\left(\mathrm{SC}_{2}\right), 7 \delta_{\mathrm{a}}\left(\mathrm{CD}_{3}\right)$ & $\rho\left(\mathrm{CD}_{3}\right)$ \\
\hline & $v_{9}$ & 756 & 747 & $763(34)$ & $760(3)$ & 0.78 & 744 & $51 \rho^{\prime}\left(\mathrm{CD}_{3}\right), 23 \rho\left(\mathrm{CD}_{3}\right), 12 v(\mathrm{SO})$ & $\rho^{\prime}\left(\mathrm{CD}_{3}\right)$ \\
\hline & $v_{10}$ & 607 & 605 & $609(4)$ & $614(68)$ & 0.13 & 606 & $63 v_{\mathrm{s}}\left(\mathrm{SC}_{2}\right), 13 \delta_{\mathrm{s}}\left(\mathrm{CD}_{3}\right), 9 \delta\left(\mathrm{SC}_{2}\right), 7 \omega\left(\mathrm{SC}_{2}\right)$ & $v_{\mathrm{s}}\left(\mathrm{SC}_{2}\right)$ \\
\hline & $v_{11}$ & 340 & 334 & $341(21)$ & $340(6)$ & 0.41 & 335 & $69 \delta\left(\mathrm{SC}_{2}\right), 14 \omega\left(\mathrm{SC}_{2}\right), 8 \rho^{\prime}\left(\mathrm{CD}_{3}\right)$ & $\delta\left(\mathrm{SC}_{2}\right)$ \\
\hline & $v_{12}$ & 262 & 273 & $266(4)$ & $263(6)$ & 0.78 & 272 & $59 \omega\left(\mathrm{SC}_{2}\right), 20 \delta\left(\mathrm{SC}_{2}\right), 8 v_{\mathrm{s}}\left(\mathrm{SC}_{2}\right)$ & $\omega\left(\mathrm{SC}_{2}\right)$ \\
\hline & $v_{13}$ & 73 & 75 & 120 & - & - & 114 & 98 tors $\left(\mathrm{CD}_{3}\right)$ & $\operatorname{tors}\left(\mathrm{CD}_{3}\right)$ \\
\hline \multirow[t]{11}{*}{$\mathrm{A}^{\prime \prime}$} & $v_{14}$ & 2253 & 2250 & $2251(12)$ & $2250(22)$ & 0.77 & 2242 & $53 v_{\mathrm{a}}\left(\mathrm{CD}_{3}\right), 45 v_{\mathrm{a}}^{\prime}\left(\mathrm{CD}_{3}\right)$ & $v_{\mathrm{a}}\left(\mathrm{CD}_{3}\right)$ \\
\hline & $v_{15}$ & 2253 & 2227 & $2242 \mathrm{sh}$ & - & - & 2218 & $53 v_{\mathrm{a}}^{\prime}\left(\mathrm{CD}_{3}\right), 45 v_{\mathrm{a}}\left(\mathrm{CD}_{3}\right)$ & $v_{\mathrm{a}}{ }^{\prime}\left(\mathrm{CD}_{3}\right)$ \\
\hline & $v_{16}$ & 2132 & 2118 & $2124(6)$ & $2125(100)$ & 0.03 & 2106 & $99 v_{\mathrm{s}}\left(\mathrm{CD}_{3}\right)$ & $v_{\mathrm{s}}\left(\mathrm{CD}_{3}\right)$ \\
\hline & $v_{17}$ & 1043 & 1008 & $1032 \mathrm{sh}$ & $1032 \mathrm{sh}$ & 0.8 & 1016 & $63 \delta_{\mathrm{a}}\left(\mathrm{CD}_{3}\right), 18 \delta_{\mathrm{a}}{ }^{\prime}\left(\mathrm{CD}_{3}\right), 9 \delta_{\mathrm{s}}\left(\mathrm{CD}_{3}\right)$ & $\delta_{\mathrm{a}}\left(\mathrm{CD}_{3}\right)$ \\
\hline & $v_{18}$ & 1025 & 996 & $1012(92)$ & $1009(21)$ & 0.15 & 1002 & $69 \delta_{\mathrm{a}}{ }^{\prime}\left(\mathrm{CD}_{3}\right), 26 \delta_{\mathrm{a}}\left(\mathrm{CD}_{3}\right)$ & $\delta_{\mathrm{a}}{ }^{\prime}\left(\mathrm{CD}_{3}\right)$ \\
\hline & $v_{19}$ & 1055 & 1062 & $1059 \mathrm{sh}$ & $1055(5)$ & 0.42 & 1043 & $65 \delta_{\mathrm{s}}\left(\mathrm{CD}_{3}\right), 20 \rho^{\prime}\left(\mathrm{CD}_{3}\right)$ & $\delta_{\mathrm{s}}\left(\mathrm{CD}_{3}\right)$ \\
\hline & $v_{20}$ & 821 & 829 & $825(36)$ & $825 \mathrm{sh}$ & - & 824 & $57 \rho\left(\mathrm{CD}_{3}\right), 11 \delta_{\mathrm{s}}\left(\mathrm{CD}_{3}\right), 10 v_{\mathrm{a}}\left(\mathrm{SC}_{2}\right), 9 \tau\left(\mathrm{SC}_{2}\right)$ & $\rho\left(\mathrm{CD}_{3}\right)$ \\
\hline & $v_{21}$ & 750 & 756 & $770 \mathrm{sh}$ & $768 \mathrm{sh}$ & $\mathrm{dp}$ & 753 & $87 \rho^{\prime}\left(\mathrm{CD}_{3}\right), 5 \tau\left(\mathrm{SC}_{2}\right)$ & $\rho^{\prime}\left(\mathrm{CD}_{3}\right)$ \\
\hline & $v_{22}$ & 615 & 609 & $622(6)$ & $625 \mathrm{sh}$ & $\mathrm{dp}$ & 613 & $48 v_{\mathrm{a}}\left(\mathrm{SC}_{2}\right), 27 \rho\left(\mathrm{CD}_{3}\right), 14 \delta_{\mathrm{a}}{ }^{\prime}\left(\mathrm{CD}_{3}\right), 9 \delta_{\mathrm{s}}\left(\mathrm{CD}_{3}\right)$ & $v_{\mathrm{a}}\left(\mathrm{SC}_{2}\right)$ \\
\hline & $v_{23}$ & 307 & 306 & $308(25)$ & $307(10)$ & 0.78 & 307 & $79 \tau\left(\mathrm{SC}_{2}\right), 16 v_{\mathrm{a}}\left(\mathrm{SC}_{2}\right)$ & $\tau\left(\mathrm{SC}_{2}\right)$ \\
\hline & $v_{24}$ & 73 & 73 & 120 & - & - & 107 & $98 \operatorname{tors}\left(\mathrm{CD}_{3}\right)$ & $\operatorname{tors}\left(\mathrm{CD}_{3}\right)$ \\
\hline
\end{tabular}

${ }^{a}$ Raman and IR frequencies are given for the fundamentals of the monomeric $\left(\mathrm{CD}_{3}\right)_{2} \mathrm{SO}$ species without strong intermolecular interactions (for a more detailed account of the bands in the $\mathrm{S}-\mathrm{O}$ stretching region, see the text and Table 4). ${ }^{b}$ From ref. $30 .{ }^{c}$ Relative intensities (in brackets) are given relative to the strongest IR band at $1053 \mathrm{~cm}^{-1}$ and Raman band at $2125 \mathrm{~cm}^{-1} ; \rho_{\text {pol }}$-depolarization ratio; notations of the normal vibrations: $v_{\mathrm{a}}\left(v_{\mathrm{a}}{ }^{\prime}\right), \delta_{\mathrm{a}}$ $\left(\delta_{\mathrm{a}}{ }^{\prime}\right)$ and $\rho\left(\rho^{\prime}\right)$ are the stretching, bending and rocking pairs of modes of $\mathrm{CH}_{3}$ groups, respectively, with dipole changes parallel (perpendicular) to the plane of symmetry; $\delta_{\mathrm{s}}\left(\mathrm{CH}_{3}\right)$ umbrella modes, $v_{\mathrm{s}}$-symmetric $\mathrm{CH}_{3}$ stretch; $v_{\mathrm{s}}\left(\mathrm{SC}_{2}\right)$ and $v_{\mathrm{a}}\left(\mathrm{SC}_{2}\right)$-symmetric and asymmetric $\mathrm{SC} \mathrm{C}_{2}$ stretch; $\delta\left(\mathrm{SC}_{2}\right), \omega\left(\mathrm{SC}_{2}\right)$ and $\tau\left(\mathrm{SC}_{2}\right)$-scissoring, wagging and twisting $\mathrm{SC}_{2}$ vibrations, respectively; tors-torsional modes. ${ }^{d}$ From normal coordinate analysis, NCA.

solutions of $\left(\mathrm{CH}_{3}\right)_{2} \mathrm{SO}$ and $\left(\mathrm{CD}_{3}\right)_{2} \mathrm{SO}$ in $\mathrm{CCl}_{4}$ are listed in Table S3. $\dagger$ The fundamental modes assigned to 'monomeric' species show some shifts from the frequencies in Tables 2 and 3 , consistent with further reduction of the weak intermolecular interactions. The IR and Raman bands below $1035 \mathrm{~cm}^{-1}$ probably belong to the rocking modes of the methyl groups. The difference of a few wavenumbers still persisting between the corresponding IR and Raman band maxima could be due to weak $\mathrm{C}-\mathrm{H} \ldots \mathrm{O}$ intermolecular interactions between neighbouring "linear" dimers in the liquid, of similar type as in the crystal structure of dimethyl sulfoxide (Fig. S $1 \dagger$ ),${ }^{4}$ or caused by the strong coupling of the rocking and $\mathrm{S}-\mathrm{O}$ stretching vibrational modes (Table 2).

Even after these experimentally based assignments, still two candidates remain in the Raman spectra for the assignment of an $\mathrm{S}-\mathrm{O}$ stretching group frequency of the $\left(\mathrm{CH}_{3}\right)_{2} \mathrm{SO}$ molecule; one is the high frequency band at $1067 \mathrm{~cm}^{-1}$, and the other a medium/weak band at $957 \mathrm{~cm}^{-1}$ (Table 2). The calculated potential energy distribution shows that $\mathrm{S}-\mathrm{O}$ stretching is dominating for both vibrational modes, but there is also strong contribution from the $\mathrm{CH}_{3}$ rocking mode, $\rho^{6}\left(\mathrm{CH}_{3}\right)$. The strongly dipolar S-O group must provide high absorption intensity for the IR stretching mode, and the isotopic shift at deuteration should be weak. Our calculations are consistent with a substantial isotopic shift to $763 \mathrm{~cm}^{-1}$ in $\left(\mathrm{CD}_{3}\right)_{2} \mathrm{SO}$ of the $957 \mathrm{~cm}^{-1}$ band, which then is assigned as $\mathrm{CH}_{3}$ rocking. Hence, the $1067 \mathrm{~cm}^{-1}$ Raman band for liquid $\left(\mathrm{CD}_{3}\right)_{2} \mathrm{SO}$ could be assigned to the $\mathrm{S}-$ O stretching mode for "monomeric" dimethyl sulfoxide species. This weak Raman band becomes the most intense at $1067.9 \mathrm{~cm}^{-1}$ in a dilute $\left(0.6 \mathrm{~mol} \mathrm{dm}^{-3}\right)$ solution of dimethyl sulfoxide in $\mathrm{CCl}_{4}$ (cf. Table 4), and has also previously been assigned to the $\mathrm{S}-\mathrm{O}$ stretch of a dimethyl sulfoxide species without specific intermolecular interactions in the liquid. ${ }^{39}$ However, the downshift ( $c$ a. $35 \mathrm{~cm}^{-1}$ ) from the $\mathrm{S}-\mathrm{O}$ stretching frequency at $1102 \mathrm{~cm}^{-1}$ in the gas phase is still substantial, and the strong dominating IR band for the dilute dimethyl sulfoxide solution at $1070.4 \mathrm{~cm}^{-1}$, deviates slightly from the Raman frequency at $1067.9 \mathrm{~cm}^{-1}$ (Table 4). These experimental observations indicate that some weak dipole-dipole interactions still persist in the dilute dimethyl sulfoxide solution in $\mathrm{CCl}_{4}$. In any case, this pair of bands (IR $1070.4 \mathrm{~cm}^{-1}$, Raman $1067.9 \mathrm{~cm}^{-1}$ ) should be the experimental data closest to the $\mathrm{S}-\mathrm{O}$ stretching group frequency of a non-interacting "monomeric" molecule in liquid dimethyl sulfoxide.

For neat liquid $\left(\mathrm{CD}_{3}\right)_{2} \mathrm{SO}$ a large number of bands (7 IR and 7 Raman, Table 4) could be detected in the S-O stretching range (Table 4). Both asymmetric and symmetric $\mathrm{CD}_{3}$ deformations are expected in this spectral region, which makes the assignment even more complicated than for liquid $\left(\mathrm{CH}_{3}\right)_{2} \mathrm{SO}$. The IR band at $1053 \mathrm{~cm}^{-1}$ and the Raman band at $1036 \mathrm{~cm}^{-1}$ are the strongest in the high frequency part of the region, and can be ascribed to the so called "closed-ring" dimeric (or polymeric) structures of antiparallel S-O dipoles (Fig. S1 $\dagger$ ). The weak isotopic shifts of these bands support this interpretation.

From the discussion above we conclude that the IR bands at 1070,1032 and $1012 \mathrm{~cm}^{-1}$ can be interpreted as the $v_{7}$, $v_{8}$ and $v_{21}$ fundamental IR modes of "monomeric" $\left(\mathrm{CH}_{3}\right)_{2} \mathrm{SO}$ molecules in the liquid, respectively, and the Raman bands at 1067 and $1010 \mathrm{~cm}^{-1}$ as the $v_{7}$ and $v_{21}$ fundamentals, respectively (cf. Tables 2, 4). For $\left(\mathrm{CD}_{3}\right)_{2} \mathrm{SO}$, the IR band at $1067.5 \mathrm{~cm}^{-1}$ and the polarized Raman band at $1071 \mathrm{~cm}^{-1}$ in dilute solution can analogously be considered as the $\mathrm{S}-\mathrm{O}$ stretching mode $v_{7}$, and the IR mode at $1046 \mathrm{~cm}^{-1}$ to $\mathrm{S}-\mathrm{O}$ stretching of associated species. Some of the remaining frequencies listed in Table 4 can be assigned as $v_{19}, v_{17}, v_{6}, v_{4}$ and $v_{18}$ modes of different $\mathrm{CD}_{3}$ deformation and rocking vibrations in the molecular species, 
and have been used in the force constant calculations. In the deuterated $\left(\mathrm{CD}_{3}\right)_{2} \mathrm{SO}$ molecule the symmetric deformation (umbrella) modes $\left(\delta_{\mathrm{s}}\right)$ of the $\mathrm{CD}_{3}$ groups, downshifted into the $1000-1060 \mathrm{~cm}^{-1}$ spectral region, interact with the $\mathrm{S}-\mathrm{O}$ stretching. The strong vibrational coupling leads to considerable intensity enhancement for the $v_{6}$ mode, $\delta_{s}\left(\mathrm{CD}_{3}\right)$, which emerges as the most intense infrared band at $1012 \mathrm{~cm}^{-1}$ for liquid $\left(\mathrm{CD}_{3}\right)_{2} \mathrm{SO}$. The other strong IR band at $1025 \mathrm{~cm}^{-1}\left(v_{4}\right)$ in this frequency range can be assigned to the asymmetric deformation mode of the $\mathrm{CD}_{3}$ group.

The other $\mathrm{C}_{2} \mathrm{SO}$ skeletal modes, i.e. the symmetric and asymmetric $\mathrm{SC}_{2}$ stretch, the $\mathrm{SC}_{2}$ scissoring, twisting and wagging modes, were observed as strong Raman bands at $698\left(v_{22}\right), 668$ $\left(v_{10}\right), 382\left(v_{11}\right), 322\left(v_{23}\right)$ and $306\left(v_{12}\right) \mathrm{cm}^{-1}$ (Table 2), which on deuteration shift to lower frequencies, $625,614,340,307$ and $263 \mathrm{~cm}^{-1}$, respectively (Table 3), with the largest relative shift for the $\mathrm{SC}_{2}$ wagging mode $v_{12}$.

Previously, no experimental observation has been reported of torsional modes for the liquids, with frequencies estimated by theoretical calculations to be in the spectral range $90-220 \mathrm{~cm}^{-1}$. The high signal/noise ratio of the modern far-infrared spectrometer revealed weak bands, which were attributed to the torsional modes $v_{13}$ and $v_{24}$. The frequencies are $102(157) \mathrm{cm}^{-1}$ for $\left(\mathrm{CH}_{3}\right)_{2} \mathrm{SO}$ and $73(120) \mathrm{cm}^{-1}$ for $\left(\mathrm{CD}_{3}\right)_{2} \mathrm{SO}$ in gas (liquid) states, respectively.

A simplified internal valence force field was established with 23 force constants refined for 48 experimental frequencies of the $\left(\mathrm{CH}_{3}\right)_{2} \mathrm{SO}$ and $\left(\mathrm{CD}_{3}\right)_{2} \mathrm{SO}$ molecules.

\section{Vibrational spectra of $\left[\mathrm{Sc}\left(\mathrm{OS}\left(\mathrm{CH}_{3}\right)_{2}\right)_{6}\right]^{3+}$}

The coordination of dimethyl sulfoxide to a metal ion induces some clear-cut changes in the vibrational spectra. These are: frequency shifts of the ligand modes, splitting of IR and Raman bands because of the interaction between coordinated $\mathrm{OSMe}_{2}$ molecules, and the appearance of new bands. The $\left[\mathrm{Sc}\left(\mathrm{OS}\left(\mathrm{CH}_{3}\right)_{2}\right)_{6}\right]^{3+}$ complex can be described in the $S_{6}$ point group, with the normal vibrations belonging to the symmetry species $11 \mathrm{~A}_{\mathrm{g}}+12 \mathrm{~A}_{\mathrm{u}}+11 \mathrm{E}_{\mathrm{g}}+12 \mathrm{E}_{\mathrm{u}}$, considering the methyl groups as point masses. The "g"-modes are Raman-active whereas the "u"-modes are IR-active.

The experimental IR and Raman fundamental frequencies for the $\left[\mathrm{Sc}\left(\mathrm{OS}\left(\mathrm{CH}_{3}\right)_{2}\right)_{6}\right]^{3+}$ and $\left[\mathrm{Sc}\left(\mathrm{OS}\left(\mathrm{CD}_{3}\right)_{2}\right)_{6}\right]^{3+}$ complexes are reported in Table 5. The assignment of the bands is based on the well-characterized spectra of dimethyl sulfoxide, aided by the results of the normal coordinate calculations. The observed new bands in the region $400-470 \mathrm{~cm}^{-1}$ can be assigned to $\mathrm{Sc}-\mathrm{O}$ stretching modes. Thus, the two IR bands at 463 and $452 \mathrm{~cm}^{-1}$, without counterpart in the dimethyl sulfoxide spectrum, could be assigned to $\mathrm{Sc}-\mathrm{O}$ stretching of $\mathrm{A}_{\mathrm{u}}$ and $\mathrm{E}_{\mathrm{u}}$ symmetry, respectively. The intensities of the Raman bands supported assignments of the strong $429 \mathrm{~cm}^{-1}$ band to the symmetric $\mathrm{A}_{\mathrm{g}}$ stretching mode, and the weak high-frequency band at $451 \mathrm{~cm}^{-1}$ to the $\mathrm{E}_{\mathrm{g}}$ mode of the $\mathrm{Sc}-\mathrm{O}$ stretching vibrations. The normal coordinate analysis showed that these modes are strongly coupled with $\mathrm{SC}_{2}$ scissoring and $\mathrm{ScOS}$ bending. The averaged Sc-O stretching frequencies are 449.6 and $429.3 \mathrm{~cm}^{-1}$ for the $\left[\mathrm{Sc}\left(\mathrm{OS}\left(\mathrm{CH}_{3}\right)_{2}\right)_{6}\right]^{3+}$ and $\left[\mathrm{Sc}\left(\mathrm{OS}\left(\mathrm{CD}_{3}\right)_{2}\right)_{6}\right]^{3+}$ complexes, respectively. The calculated mass dependence of deuteration (isotopic shift) for the $\mathrm{Sc}-\mathrm{O}$ stretch of an $\mathrm{Sc}-\mathrm{OL}_{6}$ complex, applying molecular masses for rigid ligands (OL), would only be $6 \mathrm{~cm}^{-1}$. Thus, the much greater shift observed experimentally (about $20 \mathrm{~cm}^{-1}$ ) when deuterating the $\left[\mathrm{Sc}\left(\mathrm{OSMe}_{2}\right)_{6}\right]^{3+}$ complex is due to the complexity of the $\mathrm{Sc}-\mathrm{O}$ stretching modes, e.g., their interaction with the isotope sensitive deformation modes.

In the $\mathrm{S}-\mathrm{O}$ stretching region a Raman doublet of medium intensity was observed with a polarized shoulder at lower frequency. The stronger, high frequency band $\left(963 \mathrm{~cm}^{-1}\right)$ was assigned to the $\mathrm{A}_{\mathrm{g}}$ symmetry species and the low frequency shoulder $\left(955 \mathrm{~cm}^{-1}\right)$ to the $\mathrm{E}_{\mathrm{g}}$ species. The strongest IR band 


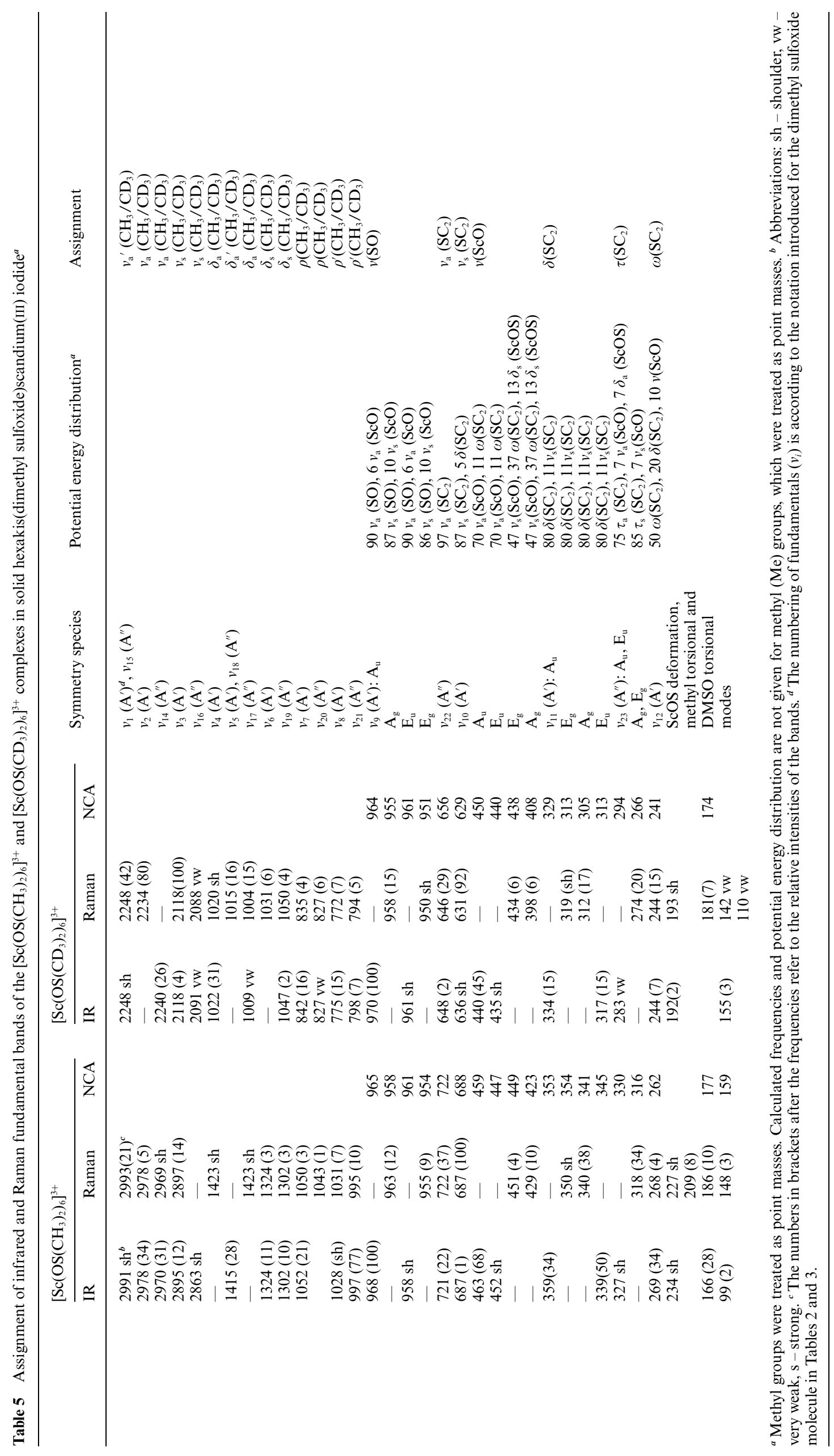


Table 6 Refined force constants for gaseous and liquid $\mathrm{Me}_{2} \mathrm{SO}$ and $\left[\mathrm{Sc}\left(\mathrm{OSMe}_{2}\right)_{6}\right]^{3+}$ complexes in solid hexakis(dimethyl sulfoxide)scandium(III) iodide $^{a}$

\begin{tabular}{|c|c|c|c|c|c|c|c|c|}
\hline Coordinates & $\begin{array}{l}\mathrm{Me}_{2} \mathrm{SO} \\
\text { (gas) }\end{array}$ & $\begin{array}{l}\mathrm{Me}_{2} \mathrm{SO} \\
\text { (liquid) }\end{array}$ & $\mathrm{C}_{2} \mathrm{~S}-\mathrm{O}^{b}$ & {$\left[\mathrm{Sc}\left(\mathrm{OSMe}_{2}\right)_{6}\right]^{3+}$} & Coordinates & $\mathrm{Me}_{2} \mathrm{SO}$ (gas) & $\begin{array}{l}\mathrm{Me}_{2} \mathrm{SO} \\
\text { (liquid) }\end{array}$ & {$\left[\mathrm{Sc}\left(\mathrm{OSMe}_{2}\right)_{6}\right]^{3+}$} \\
\hline Stretching & & & & & Stretch-bend & & & \\
\hline$K(\mathrm{CH})$ & 4.822 & 4.777 & - & - & $k\left(\mathrm{CH}, \mathrm{CH}_{2}\right)$ & 0.100 & 0.100 & - \\
\hline$K(\mathrm{CS})$ & 2.064 & 2.051 & 2.060 & 2.194 & $k(\mathrm{CH}, \mathrm{SCH})$ & -0.100 & -0.100 & - \\
\hline$K(\mathrm{SO})$ & 5.061 & 4.717 & 5.060 & $4.402(4.653)^{c}$ & $k(\mathrm{SO}, \mathrm{SCH})$ & 0.048 & 0.024 & - \\
\hline$K(\mathrm{ScO})$ & - & - & - & $1.462(1.643)^{c}$ & $k(\mathrm{SO}, \mathrm{SCH})$ & -0.210 & -0.210 & - \\
\hline Stretch-stretch & & & & & $k\left(\mathrm{SC}, \mathrm{CH}_{2}\right)$ & -0.061 & -0.099 & - \\
\hline$F(\mathrm{CH}, \mathrm{CH})$ & 0.059 & 0.066 & - & - & $k(\mathrm{SC}, \mathrm{SCH})$ & -0.144 & -0.144 & - \\
\hline$F(\mathrm{CS}, \mathrm{CS})$ & 0.225 & 0.208 & 0.230 & 0.119 & $k\left(\mathrm{SC}, \mathrm{SC}_{2}\right)$ & 0.433 & 0.433 & - \\
\hline$F(\mathrm{SO}, \mathrm{SO})^{d}$ & - & - & - & -0.173 & $k(\mathrm{CS}, \mathrm{SCO})$ & 0.069 & 0.062 & -0.123 \\
\hline$F(\mathrm{ScO}, \mathrm{ScO})$ & - & - & - & 0.451 & $k(\mathrm{CS}, \mathrm{SCO})^{f}$ & -0.097 & -0.090 & \\
\hline Bending & & & & & Bend-bend & & & \\
\hline $\mathrm{H}\left(\mathrm{CH}_{2}\right)$ & 0.474 & 0.473 & - & - & $h(\mathrm{SCH}, \mathrm{SCH})$ & 0.012 & 0 & - \\
\hline$H\left(\mathrm{SC}_{2}\right)$ & 1.506 & 1.522 & 1.141 & 0.862 & $h\left(\mathrm{CH}_{2}, \mathrm{SCH}\right)$ & -0.012 & -0.012 & - \\
\hline$H(\mathrm{CSO})$ & 1.075 & 1.070 & 0.947 & 0.513 & $h\left(\mathrm{SC}_{2}, \mathrm{CSO}\right)$ & -0.023 & -0.023 & - \\
\hline$H(\mathrm{SCH})$ & 0.702 & 0.708 & - & - & $h$ (tors, tors) & 0.002 & 0 & - \\
\hline$H$ (OSCH tors) & 0.046 & 0.020 & - & - & & & & \\
\hline
\end{tabular}

${ }^{a}$ Force constant units: stretching $(K, F)$ in $10^{-2} \mathrm{~N} \mathrm{~m}^{-1}$, stretching-bending $(k)$ and bending-bending $(h)$ in $10^{-6} \mathrm{~N}$ rad ${ }^{-1}$, and bending $(H)$ in $10^{-16} \mathrm{~N}$ $\mathrm{m} \mathrm{rad}^{-2} \cdot{ }^{b}$ Methyl groups treated as point masses. ${ }^{c} \mathrm{ScO}$ and SO stretching force constants within parentheses obtained using a simplified monoligand $\mathrm{Sc}-\mathrm{OSC}_{2}$ model. ${ }^{d}$ Only the interaction between centrosymmetric ligands was taken into account. ${ }^{e}$ Interaction with $\mathrm{SCH}$ angle not in plane with $\mathrm{S}-\mathrm{O} .{ }^{f}$ Sulfur is the only common atom.

in the infrared spectra is a well-defined doublet at $968 \mathrm{~cm}^{-1}$ with a shoulder at $958 \mathrm{~cm}^{-1}$ of $\mathrm{A}_{\mathrm{u}}$ and $\mathrm{E}_{\mathrm{u}}$ symmetry species, respectively. According to the calculations, deuteration does not significantly shift these bands, which supports the assignment.

Two Raman bands near $700 \mathrm{~cm}^{-1}$ were attributed to the $\mathrm{SC}_{2}$ asymmetric $\left(722 \mathrm{~cm}^{-1}\right)$ and symmetric $\left(687 \mathrm{~cm}^{-1}\right)$ stretching modes; the latter is the most intense Raman band in the spectrum. The absence of splitting indicates weak coupling of these ligand modes. In the IR spectra the corresponding modes occur at the very same frequencies. Deuteration of the dimethyl sulfoxide molecule leads to significant downshifts by 76 and $56 \mathrm{~cm}^{-1}$ for the asymmetric and symmetric $\mathrm{SC}_{2}$ stretching modes, respectively.

All skeletal deformation modes of dimethyl sulfoxide $\left(v_{11}, v_{12}\right.$ and $v_{23}$ ) were downshifted at coordination. Two well-defined intense IR bands at 359 and $339 \mathrm{~cm}^{-1}$ can be assigned to $\mathrm{SC}_{2}$ scissoring $\left(v_{11}\right)$ modes of $\mathbf{A}_{u}$ and $\mathrm{E}_{\mathrm{u}}$ symmetry species, respectively. The strong Raman band at $340 \mathrm{~cm}^{-1}$ can be assigned as a mode of $\mathrm{A}_{\mathrm{g}}$ symmetry, and the shoulder at higher frequency $\left(350 \mathrm{~cm}^{-1}\right)$ as $\mathrm{E}_{\mathrm{g}}$ symmetry. A similar pattern was observed for the deuterated $\left[\mathrm{Sc}\left(\mathrm{OS}\left(\mathrm{CH}_{3}\right)_{2}\right)_{6}\right]^{3+}$ complex with downshifted skeletal ligand modes at coordination, with the largest shift from 269 to $244 \mathrm{~cm}^{-1}$ for the $\mathrm{SC}_{2}$ wagging mode $\left(v_{12}\right)$ appearing as a strong IR band. The absence of splitting of these bands in the Raman and IR spectra again indicates very weak vibrational coupling.

The $\mathrm{SC}_{2}$ twisting mode $\left(v_{23}\right)$ was assigned to a strong Raman band at $318 \mathrm{~cm}^{-1}\left(274 \mathrm{~cm}^{-1}\right.$ in $\left.\left[\mathrm{Sc}\left(\mathrm{OS}\left(\mathrm{CD}_{3}\right)_{2}\right)_{6}\right]^{3+}\right)$. Vibrational frequencies at 234, 166 and $99 \mathrm{~cm}^{-1}$ in the far-IR spectrum and 227, 209, 186 and $148 \mathrm{~cm}^{-1}$ in the Raman spectrum could be tentatively attributed to $\mathrm{ScOS}$ deformation and ligand torsional modes. The deformation modes of the $\mathrm{ScO}_{6}$ polyhedra and the $\mathrm{ScO}$ torsions should be lower than $100 \mathrm{~cm}^{-1}$, and no experimental frequencies could reliably be assigned to these modes (Table 5).

\section{Discussion}

\section{Interactions in dimethyl sulfoxide}

To evaluate the effect of intermolecular interactions involving the methyl group protons, the force constants were refined for vibrational frequencies obtained for acetone and dimethyl sulfoxide in the gas phase and liquid, also including deuterated molecules. The averaged $\mathrm{C}-\mathrm{H}$ stretching frequencies decreased from gas phase to liquid for acetone from 2974.5 to
$2962.5 \mathrm{~cm}^{-1},{ }^{43,44}$ and for dimethyl sulfoxide from 2984.3 to $2963.2 \mathrm{~cm}^{-1}$. Similar effects were established for the C-D stretching frequencies (Table 3 ). The $\mathrm{C}-\mathrm{H}$ stretching force constants decreased by $0.80 \%$ for acetone $\left(0.04790\right.$ and $0.04751 \mathrm{~N} \mathrm{~m}^{-1}$ for gas and liquid, respectively) and by $0.93 \%$ for dimethyl sulfoxide (Table 6). The $\mathrm{CH} / \mathrm{CD}$ stretchings are very specific as group diagnostic wavenumbers since they are not mixed substantially with other vibrational modes, and the evaluations of the C-H/D stretching force constants were performed in a consistent way to allow comparisons. Therefore, these relatively small changes of the force constants should have real physical meaning and can be interpreted as evidence of weak intermolecular $\mathrm{C}\left(\mathrm{sp}^{3}\right)$ $\mathrm{H} / \mathrm{D}$... O interactions in liquid acetone and dimethyl sulfoxide. The slightly larger decrease of the $\mathrm{C}-\mathrm{H} / \mathrm{D}$ stretching force constant for dimethyl sulfoxide than for acetone is consistent with other criteria, e.g. ${ }^{17} \mathrm{O}$ NMR chemical shifts, showing the interactions to be weaker for acetone. ${ }^{7 a, 8}$

Other, more noticeable changes take place for the $\mathrm{S}-\mathrm{O}$ stretching vibrational mode, which has a more complex character. The $\mathrm{S}-\mathrm{O}$ stretching frequency decreases substantially from gas to liquid for dimethyl sulfoxide (Tables 2, 3), and the corresponding force constant is reduced by almost $9 \%$ (Table 6). This externally induced effect exceeds by far the relative changes expected from weak $\mathrm{C}-\mathrm{H}$... O interactions, and supports strong dipole-dipole interactions between dimethyl sulfoxide molecules in the liquid.

A dimer of antiparallel $\mathrm{S}-\mathrm{O}$ dipoles of two neighbouring dimethyl sulfoxide molecules would create an inversion centre in approximately $C_{2 \mathrm{~h}}$ symmetry and separate the Raman and IR bands for liquid dimethyl sulfoxide in the $\mathrm{S}-\mathrm{O}$ stretching region around $1000 \mathrm{~cm}^{-1}$. This is consistent with the difference between the IR and Raman frequencies for the $\mathrm{S}-\mathrm{O}$ stretch (Table 4), and also with the behaviour of the strong interaction with $\mathrm{CH}_{3}$ rocking for $\left(\mathrm{CH}_{3}\right)_{2} \mathrm{SO}$, and with the $\mathrm{CD}_{3}$ umbrella mode for $\left(\mathrm{CD}_{3}\right)_{2} \mathrm{SO}$ (shown by the calculated potential energy distribution), $c f$. Results and Tables 2 and 3. The $\mathrm{CH}_{3}$ rocking $\left(v_{20}\right)$, strongly coupled with the $\mathrm{S}-\mathrm{O}$ stretch, shows a similar separation $\left(1032 / 1029 \mathrm{~cm}^{-1}\right)$. For the $\left(\mathrm{CD}_{3}\right)_{2} \mathrm{SO}$ molecule the splitting of the $\mathrm{S}-\mathrm{O}$ stretching frequencies for the IR and Raman bands at 1053 and $1061 \mathrm{~cm}^{-1}$, and of $\mathrm{CD}_{3}$ symmetric deformations $\left(v_{6}\right)$ at 1012 and $1007 \mathrm{~cm}^{-1}$, also supports their interpretation as $B_{u}$ and $A_{g}$ modes, respectively, due to vibrational resonance coupling of antiparallel dipoles in $D_{2 \mathrm{~h}}$ symmetry.

The above discussion of the intricate behaviour of the $\mathrm{S}-\mathrm{O}$ stretching mode in dimethyl sulfoxide, both for $\left(\mathrm{CH}_{3}\right)_{2} \mathrm{SO}$ and 
$\left(\mathrm{CD}_{3}\right)_{2} \mathrm{SO}$ molecules, shows that conclusions about coordination and bonding properties simply from frequency shifts in the $\mathrm{S}$ $\mathrm{O}$ stretching region should be carefully considered. In addition to the intermolecular dipole-dipole and $\mathrm{C}-\mathrm{H} \ldots \mathrm{O}$ interactions, our normal coordinate calculations reveal that intramolecular contributions from deformation and rocking vibrations of the methyl group, and changes in the molecular geometry, namely the $\mathrm{C}-\mathrm{S}-\mathrm{C}$ and $\mathrm{O}-\mathrm{S}-\mathrm{C}$ bond angles, also influence the $\mathrm{S}-$ $\mathrm{O}$ stretching frequency. These effects can spectroscopically be taken into account as additional factors to other coordination effects influencing the $\mathrm{S}-\mathrm{O}$ stretching frequency in dimethyl sulfoxide ligands, i.e. the character and strength of the metal-ligand bond, the internal electron displacement due to the $\mathrm{M}-\mathrm{O} \sigma$-bonding and backbonding from metal d-orbitals. This is one reason why a relationship only considering $\mathrm{S}-\mathrm{O}$ stretching frequencies and bond lengths, as the one published recently by Calligaris (that also includes doubtful assignments for $\mathrm{Pd}\left(\mathrm{NO}_{2}\right)($ pyi $)(\mathrm{dmso}-O)$ and $\left.\left(\mathrm{HgCl}_{2}\right)_{3}(\mathrm{dmso}-O)_{2}\right),{ }^{1}$ shows a rather diffuse correlation.

The torsion mode is also strongly affected by the aggregation state. The hindered rotation of the methyl groups in liquid dimethyl sulfoxide more than doubled the corresponding force constant and increased the torsional frequencies by $55 \mathrm{~cm}^{-1}$ for $\left(\mathrm{CH}_{3}\right)_{2} \mathrm{SO}$ and $47 \mathrm{~cm}^{-1}$ for $\left(\mathrm{CD}_{3}\right)_{2} \mathrm{SO}$. Most other $\mathrm{OSMe}_{2}$ skeletal modes do not change significantly between the gaseous and liquid state, some bands decrease and some increase by $5-6 \mathrm{~cm}^{-1}$.

\section{Hexacoordinated metal(III)-dimethyl sulfoxide solvates}

Theoretical studies have previously been performed on dimethyl sulfoxide molecules solvating the triply charged scandium(III) ion in the gas phase. The octahedrally coordinated $\left[\mathrm{Sc}(\mathrm{OSMe})_{6}\right)^{3+}$ species, with a computed $\mathrm{Sc}-\mathrm{O}$ bond distance of $2.122 \AA$, was found to be thermodynamically stable with respect to all dissociation processes considered in the gas phase, demonstrating the strong $\mathrm{Sc}-\mathrm{O}$ interaction and the stability of dimethyl sulfoxide as ligand. ${ }^{45}$

The Sc-O bond distance 2.069(3) $\AA$ in the crystal structure of hexakis(dimethyl sulfoxide)scandium(III) iodide is very close to the $\mathrm{Sc}-\mathrm{O}$ bond distance 2.068(6) $\AA$ for the major component ( $86 \%$ occupancy) of the recently published disordered crystal structure of $\left[\mathrm{Sc}\left(\mathrm{OSMe}_{2}\right)_{6}\right]\left(\mathrm{ClO}_{4}\right)_{3},{ }^{26}$ and also the $\mathrm{Sc}-\mathrm{O}$ distances between 2.06 and $2.08 \AA$ in $\left[\mathrm{Sc}(\mathrm{NCS})_{3}\left(\mathrm{OSMe}_{2}\right)_{3}\right] .{ }^{27}$ In several crystalline hydrates, scandium(III) coordinates seven or eight water molecules, and for the hydrated scandium(III) ion in aqueous solution the reported $\mathrm{Sc}-\mathrm{O}$ bond distances are in the range $2.15-2.18 \AA$, consistent with a coordination of at least seven water molecules..$^{20,46,47}$ However, the EXAFS spectra for the solvated scandium(III) ion in dimethyl sulfoxide solution reveal mean $\mathrm{Sc}-\mathrm{O}$ and $\mathrm{Sc} \ldots \mathrm{S}$ distances of 2.09(1) and 3.34(2) $\AA$, respectively, fairly close to the corresponding crystallographic distances for the hexasolvate in $\left[\mathrm{Sc}\left(\mathrm{OSMe}_{2}\right)_{6}\right] \mathrm{I}_{3}$, 2.069(3) and 3.308(2) $\AA$. Moreover, the mean Sc-O distances $2.085(6)$ and 2.078(6) $\AA$ for the hexaaquascandium(III) and hexakis(mesylato)scandate(III) complexes, respectively, in the crystal structure of $\left[\mathrm{Sc}\left(\mathrm{H}_{2} \mathrm{O}\right)_{6}\right]\left[\mathrm{Sc}\left(\mathrm{OSO}_{2} \mathrm{CH}_{3}\right)_{6}\right],{ }^{20}$ support the solvation number six in dimethyl sulfoxide solution.

In solution the oxygen-coordinated dimethyl sulfoxide ligands would be able to rotate around the $\mathrm{M}-\mathrm{O}$ bond, corresponding to the inverted orientations observed for the disordered crystal structures. ${ }^{24-27}$ The steric demands of rotating $\mathrm{OSMe}_{2}$ ligands, retaining an $\mathrm{Sc}-\mathrm{O}-\mathrm{S}$ angle of about $133^{\circ}$ within an $\left[\mathrm{Sc}\left(\mathrm{OSMe}_{2}\right)_{6}\right]^{3+}$ complex, is probably the reason why the scandium(III) solvation number is lower in dimethyl sulfoxide than in aqueous solution.

Raman spectroscopy of $1 \mathrm{~mol} \mathrm{dm}^{-3}$ alkali halide solutions in dimethyl sulfoxide has shown that interactions between iodide ions and the methyl groups give rise to a $\mathrm{CH}_{3}$ asymmetric stretching frequency component at about $2975-2980 \mathrm{~cm}^{-1}$ (in deuterated dimethyl sulfoxide $2238 \mathrm{~cm}^{-1}$ ), downshifted about
$15 \mathrm{~cm}^{-1}$ from the band in neat dimethyl sulfoxide. This was interpreted as a direct interaction between the two methyl groups of about 3 dimethyl sulfoxide molecules and the iodide ions, and modelled in an X-ray diffraction study with an $\mathrm{S} \cdots \mathrm{I}^{-}$ distance of $4.37 \AA{ }^{47}$ An attractive interaction between the iodide ion and the positive sulfur end of the dipole in dimethyl sulfoxide, restricted and partly reduced by interference with the methyl groups, is revealed from ab initio quantum chemical studies. ${ }^{48,49}$ Also for the $\left[\mathrm{Sc}\left(\mathrm{OSMe}_{2}\right)_{6}\right] \mathrm{I}_{3}$ compound the $\mathrm{C}-\mathrm{H} / \mathrm{D}$ stretching frequencies show small downshifts compared to neat dimethyl sulfoxide (mean about $10-15 \mathrm{~cm}^{-1}, c f$. Tables 2, 3 and 5 ), consistent with a similar, slightly stronger effect of the $\mathrm{C}-$ $\mathrm{H} \cdots \mathrm{I}^{-}$interactions in the solid compound, than caused by the $\mathrm{C}-\mathrm{H} \cdots \mathrm{O}$ interactions in the neat liquid. The $\mathrm{C}(-\mathrm{H}) \cdots \mathrm{I}^{-}$ distances between 3.98 and $4.33 \AA$, mean $4.14 \AA$, are longer than normally attributed to hydrogen bonding with acidic protons, but are in the range expected for iodide ion contacts with e.g. the methyl groups of quaternary ammonium ions where the coulombic $\mathrm{N}^{+} \ldots \mathrm{I}^{-}$attraction probably is important. ${ }^{7 a}$ The electrostatic ion-dipole attraction to the sulfur atom of the $\mathrm{S}-\mathrm{O}$ group (closest $\mathrm{S} \cdots \mathrm{I}^{-}$distance $4.30 \AA$ in the crystal structure of $\left.\left[\mathrm{Sc}\left(\mathrm{OSMe}_{2}\right)_{6}\right] \mathrm{I}_{3}\right)$ probably contributes the main part of the attractive interaction energy of the iodide ion, even though the theoretical calculations show some positive charge on the methyl hydrogen atoms. ${ }^{1}$ However, the vibrational spectra reveal that the methyl-iodide ion interference influences the $\mathrm{C}-\mathrm{H} / \mathrm{D}$ stretching frequencies, even though this interaction seems to be caused mainly by the long-range electrostatic ion-dipole attraction affecting the intermediate methyl group, rather than a "weak hydrogen bond" between two electronegative atoms. ${ }^{7 a}$

The results obtained from normal coordinate analyses of the vibrational spectra for the $\left[\mathrm{Sc}\left(\mathrm{OSMe}_{2}\right)_{6}\right]^{3+}$ complex and the previously studied hexacoordinated Group $13\left[\mathrm{M}\left(\mathrm{OSMe}_{2}\right)_{6}\right]^{3+}$ solvates $(\mathrm{M}=\mathrm{Al}, \mathrm{Ga}, \mathrm{In}, \mathrm{Tl}){ }^{15,16}$ allow comparisons of the effect of the size of the trivalent metal ions and their electronic structure on the coordination. The correlation between the $\mathrm{M}-$ $\mathrm{O}$ stretching force constants and the $\mathrm{M}-\mathrm{O}$ bond distance in Fig. 5 is almost linear with some deviation for the $\left[\mathrm{Tl}\left(\mathrm{OSMe}_{2}\right)_{6}\right]^{3+}$ solvate, which has substantial covalent bond character as shown by comparing the sulfur K-edge X-ray absorption spectra of the Group $13\left[\mathrm{M}\left(\mathrm{OSMe}_{2}\right)_{6}\right]^{3+}$ solvates. $^{50}$

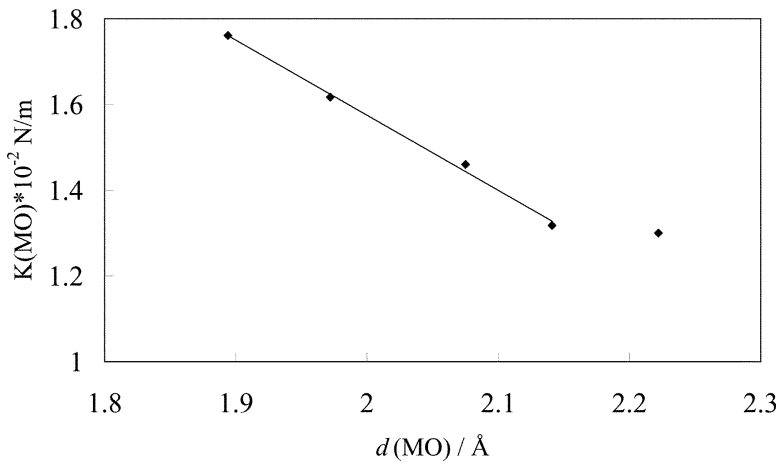

Fig. 5 Correlation between stretching $\mathrm{M}-\mathrm{O}$ force constants and corresponding bond distances (in the order $\mathrm{M}=\mathrm{Al}^{3+}<\mathrm{Ga}^{3+}<\mathrm{Sc}^{3+}<$ $\left.\mathrm{In}^{3+}<\mathrm{Tl}^{3+}\right)$

The coordination to metal ions via oxygen decreases the $\mathrm{S}$ $\mathrm{O}$ stretching frequencies and the corresponding force constant, while the $\mathrm{C}-\mathrm{S}$ stretching frequencies and force constant increase as compared to free dimethyl sulfoxide. Generally, the stronger the $\mathrm{M}-\mathrm{O}$ bond is, the smaller the $\mathrm{S}-\mathrm{O}$ stretching frequencies and the corresponding force constants become. However, we do not obtain a strict correlation between the $\mathrm{S}-\mathrm{O}$ or $\mathrm{M}-\mathrm{O}$ bond distances and the $\mathrm{S}-\mathrm{O}$ force constants. ${ }^{15}$ For the aluminium and scandium complexes the $\mathrm{S}-\mathrm{O}$ stretching force constants are significantly higher than expected, probably because these $\mathrm{d}^{0}$ ions lack back-bonding possibility. For the $\mathrm{d}^{10}$ ions, gallium(III), 
indium(III) and thallium(III), back-bonding can increase the M$\mathrm{O}$ bond strength, which then causes a weakening of the $\mathrm{S}-\mathrm{O}$ bond. The contribution of $\mathrm{M}-\mathrm{O}$ stretching to the $\mathrm{S}-\mathrm{O}$ stretching group frequency near $950-970 \mathrm{~cm}^{-1}$ decreases significantly from the solvates of the Group 13 metal ions to scandium(III), which also correlates to a substantial increase in the MOS angle (from ca. $124^{\circ}$ to $\left.132.6^{\circ}\right) .{ }^{15}$

The coordination of the dimethyl sulfoxide molecule leads to a significant decrease in the $\mathrm{SC}_{2}$ scissoring vibrational frequencies and the corresponding bending force constants, and increases the $\mathrm{S}-\mathrm{C}$ stretching frequencies and the SC stretching force constants. The $\mathrm{SC}_{2}$-deformation, the $\mathrm{ScOS}$ bending and the $\mathrm{S}_{-}$ $\mathrm{O}$ torsional vibrations are strongly coupled, and the potential energy distribution (PED) shows the interaction between the different modes. There is significant interaction between the Sc$\mathrm{O}$ stretching and $\mathrm{SC}_{2}$ wagging modes consistent with a hindered deformation of dimethyl sulfoxide as ligand. Comparison with the Group 13 metal dimethyl sulfoxide solvates shows similar coupling for the gallium(III), indium(III) and thallium(III) ions. ${ }^{15}$

\section{Conclusions}

Complete assignments of the vibrational frequencies for gaseous and liquid dimethyl sulfoxide and their fully deuterated analogues have been achieved. A small well-defined decrease of the $\mathrm{C}-\mathrm{H}$ stretching frequencies provides evidence of weak $\mathrm{C}-\mathrm{H} \cdots \mathrm{O}$ interactions in liquid dimethyl sulfoxide, even though the substantial shift of the $\mathrm{S}-\mathrm{O}$ stretching modes to lower wavenumbers reveals that intermolecular dipole-dipole interactions between the $\mathrm{S}-\mathrm{O}$ groups have a more prominent effect on the spectral characteristics. The interactions in liquid dimethyl sulfoxide split the $\mathrm{S}-\mathrm{O}$ frequencies by resonance coupling of vibrational modes and decrease the $\mathrm{S}-\mathrm{O}$ stretching force constants.

The crystal structure of hexakis(dimethyl sulfoxide)scandium(III) iodide showed highly symmetric hexasolvated scandium(III) ions with the mean Sc-O bond distance 2.069(3) $\AA$. EXAFS spectra of scandium(III) in dimethyl sulfoxide solution resulted in a mean $\mathrm{Sc}-\mathrm{O}$ bond distance of 2.09(1) $\AA$, consistent with hexasolvated species. The solvation number in solution probably is restricted by the steric requirements of the dimethyl sulfoxide ligands, able to perform rotational inversions around the $\mathrm{Sc}-\mathrm{O}$ bond.

Normal coordinate analysis of the vibrational spectra of the hexakis(dimethyl sulfoxide)scandium(III) complex showed substantial changes in the vibrational frequencies of the coordinated dimethyl sulfoxide molecules. A slight but significant decrease of the $\mathrm{C}-\mathrm{H}$ stretching frequencies indicates interactions with the iodide ions. The force constants of the $\mathrm{S}-\mathrm{O}$ stretching and the dimethyl sulfoxide skeletal and deformation modes decrease, whereas the $\mathrm{C}-\mathrm{S}$ stretching force constants increase. Generally, there is strong coupling of the skeletal dimethyl sulfoxide vibrations in the $\mathrm{S}-\mathrm{O}$ stretching region, and the force constants are more reliable indicators of a change in bond character for a dimethyl sulfoxide solvate than the position of a vibrational band assigned as the $\mathrm{S}-\mathrm{O}$ group frequency.

\section{Acknowledgements}

We gratefully acknowledge the Swedish Research Council, the Wenner-Gren Foundations and the Hungarian National Research Foundation (OTKA T025278 and TO35115) for financial support. X-Ray absorption measurements were carried out at Stanford Synchrotron Radiation Laboratory (SSRL), a national user facility operated by Stanford University on behalf of the U.S. Department of Energy, Office of Basic Energy Sciences. The Swedish Foundation for International Cooperation in Research and Higher Education (STINT) is acknowledged for grants towards travel expenses and the Swedish Institute for support through the Visby programme. The Swedish and Hungarian Academies of Science are acknowledged for the support of our cooperation. We wish to thank Dr Eva Bencze for assistance in spectroscopic experiments and normal coordinate calculations and Dr Olof Kristiansson for single-crystal X-ray experiments.

\section{References}

1 M. Calligaris, Coord. Chem. Rev., 2004, 248, 351.

2 S. Itoh and H. Ohtaki, Z. Naturforsch., Teil A, 1987, 42, 858.

3 H. Bertagnolli, E. Schultz and P. Chieux, Ber. Bunsenges. Phys. Chem., 1989, 93, 88

4 R. Thomas, C. B. Shoemaker and K. Eriks, Acta Crystallogr., 1966, 21, 12 .

5 N. L. Allinger, Y. Fan and T. Varnali, J. Phys. Org. Chem., 1996, 9, 159.

6 H. Borrmann, I. Persson, M. Sandström and C. M. V. Stålhandske, J. Chem. Soc., Perkin Trans. 2, 2000, 393.

7 (a) G. R. Desiraju and T. Steiner, The Weak Hydrogen Bond, $\mathrm{IUCr}$ Monographs on Crystallography, No. 9, Oxford University Press, Oxford, 1999, ch. 2 and 3.3; (b) T. Steiner, Angew. Chem. Int. Ed., 2002, 41, 48.

8 M. Sandström, I. Persson and P. Persson, Acta Chem. Scand., 1990, 44, 653 .

9 F. A. Cotton, R. Francis and W. D. Horrocks, J. Phys. Chem., 1960, 64, 1534.

10 F. A. Cotton and R. Francis, J. Am. Chem. Soc., 1960, 82, 2986.

11 W. D. Horrocks and F. A. Cotton, Spectrochim. Acta, 1961, 17, 134.

12 B. F. G. Johnson and R. A. Walton, Spectrochim. Acta, 1966, 22, 1853.

13 C. V. Berney and J. H. Weber, Inorg. Chem., 1968, 7, 283.

14 M. Sandström, I. Persson and S. Ahrland, Acta Chem. Scand., Ser. A, 1978, 32, 607 .

15 A. Molla-Abbassi, M. Skripkin, M. Kritikos, I. Persson, J. Mink and M. Sandström, Dalton Trans., 2003, 1746.

16 G. Ma, A. Molla-Abbassi, M. Kritikos, A. Ilyukhin, F. Jalilehvand, V. Kessler, M. Skripkin, M. Sandström, J. Glaser, J. Näslund and I. Persson, Inorg. Chem., 2001, 40, 6432.

17 P. Lindqvist-Reis, J. Näslund, I. Persson and M. Sandström, J. Chem. Soc., Dalton Trans., 2000, 2703.

18 J. Näslund, P. Lindqvist-Reis, I. Persson and M. Sandström, Inorg. Chem, 2000, 39, 4006

19 A. Abbasi, M. Yu. Skripkin, Y. Sidorov, J. Mink, I. Persson and M. Sandström, to be published.

20 P. Lindqvist-Reis, Structure of Solvated Metal Ions, Doctoral Thesis, Royal Institute of Technology (KTH), Stockholm, Sweden, 2000; available at http://www.lib.kth.se/Sammanfattningar/ reis000614.pdf.

21 F. J. Waller, A. G. M. Barret, D. C. Braddock, D. Ramprasad, R. M. McKinnel, A. J. P. White, D. J. Williams and R. Duckray, J. Org. Chem., 1999, 64, 2910.

22 K. C. Lim, B. W. Skelton and A. H. White, Aust. J. Chem., 2000, 53, 875 .

23 A. Abbasi, P. Lindqvist-Reis, L. Eriksson, I. Persson, D. Sandström and M. Sandström, unpublished results.

24 M. Sandström, Acta Chem. Scand., Ser. A, 1978, 32, 519

25 O. Kristiansson and P. Lindqvist-Reis, Acta Crystallogr., Sect. C, 2000, 56, 163

26 E. J. Chan, B. G. Cox, J. M. Harrowfield, M. I. Ogden, B. W. Skelton and A. H. White, Inorg. Chim. Acta, 2004, 357, 2365.

27 V. Chenskaya, A. V. Virovets, S. A. Gromilov, N. V. Podberezskaya and T. G. Cherkasova, Inorg. Chem. Commun., 2000, 3, 482.

28 J. W. Cubbage and W. S. Jenks, J. Phys. Chem. Ser. A, 2001, 105, 10588.

29 R. G. Pearson, Chem. Br., 1967, 3, 103.

30 M. Tranquille, P. Labarre, M. Fouassier and M. T. Forel, J. Mol. Struct., 1971, 8, 273.

31 G. Geiseler and G. Hanschmann, J. Mol. Struct., 1971, 8, 293.

32 SMART (version 5.046), SAINT, 5.01 (integration software), SAD$A B S$ (empirical absorption correction), Bruker Analytical X-ray Systems, Madison, WI, 1998.

33 G. M. Sheldrick, SHELXTL PLUS 1992, University of Göttingen, Germany, 1992.

34 T. Ressler, J. Synchrotron Rad., 1998, 5, 118, http://www.winxas.de/.

35 G. N. George and I. J. Pickering, EXAFSPAK - A Suite of Computer Programs for EXAFS Analysis, SSRL, Stanford University, CA., USA, 1993, http://www-ssrl.slac.stanford.edu/exafspak.html.

36 (a) A. Filipponi and A. Di Cicco, Phys. Rev. B, 1995, 52, 15135; (b) A. Filipponi, A. Di Cicco and C. R. Natoli, Phys. Rev. B, 1995, 52, 15122, see http://www.aquila.infn.it/gnxas/.

37 S. L. Zabinsky, J. J. Rehr, A. Ankudinov, R. C. Albers and M. J. Eller, J. Phys. Rev. B, 1995, 52, 2995, see http://leonardo.phys. washington.edu/feff/. 
38 J. Mink and L. M. Mink, Computer Program System for Vibrational Analyses of Polyatomic Molecules (in Lahey-Fujitsu Fortran Win32), Stockholm, 2004.

39 M. T. Forel and M. Tranquille, Spectrochim. Acta, Part A, 1970, 26, 1023.

40 J. B. Gill, D. C. Goodall, B. Jeffrey and P. Gans, J. Chem. Soc., Dalton Trans., 1986, 2597.

41 M. I. S. Sastry and S. Singh, J. Raman Spectrosc., 1980, 15, 80.

42 K. Wakabayashi, Y. Maeda, K. Ozutsumi and H. Ohtaki, J. Mol. Liq., 2004, 110, 43.

43 P. Cossee and J. H. Schachtschneider, J. Chem. Phys., 1966, 44, 97.

44 G. Dellepiane and J. Overend, Spectrochim Acta, 1966, 22, 593.
45 C. Xiao, F. Hagelberg and A. M. El-Nahas, J. Phys. Chem. A, 2004, 108, 5322.

46 T. Yamaguchi, M. Niihara, T. Takamuku, H. Wakita and H. Kanno, J. Chem. Phys. Lett., 1997, 274, 485.

47 P. Smirnov, H. Wakita and T. Yamaguchi, J. Phys. Chem. B, 1998, 102, 4802.

48 U. Onthong, I. Bako, T. Radnai, K. Hermansson and M. Probst, Int. J. Mass Spectrosc., 2003, 223-224, 263.

49 T. F. Magnera, G. Caldwell, J. Sunner, S. Ikuta and P. Kebarle, J. Am. Chem. Soc., 1984, 106, 6140.

50 E. Damian, A. Molla-Abbassi, F. Jalilehvand, L. G. M. Pettersson and M. Sandström, Phys. Scripta, 2004, in the press. 